Graduate Institute of International and Development Studies International Economics Department Working Paper Series

\title{
Firm Response to Competitive Shocks: Evidence from Chinas Minimum Wage Policy
}

\author{
Harald Hau \\ University of Geneva and Swiss Finance Institute \\ Yi Huang \\ Graduate Institute of International and Development Studies \\ Gewei Wang \\ Graduate Institute of International and Development Studies
}

Chemin Eugène-Rigot 2

P.O. Box 136

CH - 1211 Geneva 21

Switzerland

(C) The Authors. All rights reserved. Working Papers describe research in progress by the author(s) and are published to elicit comments and to further debate. No part of this paper may be reproduced without the permission of the authors. 


\title{
Firm Response to Competitive Shocks: Evidence from China's Minimum Wage Policy
}

\author{
Harald Hau* \\ University of Geneva and Swiss Finance Institute \\ Yi Huang** \\ Graduate Institute of International and Development Studies \\ Gewei Wang*** \\ Graduate Institute of International and Development Studies
}

July 22,2016

\begin{abstract}
The large regional variation of minimum wage changes in 2002-08 implies that Chinese manufacturing firms experienced competitive shocks as a function of firm location and their low-wage employment share. We find that minimum wage hikes accelerate the input substitution from labor to capital in low-wage firms, reduce employment growth, but also accelerate total factor productivity growth - particularly among the less productive firms under private Chinese or foreign ownership, but not among state-owned enterprises. The heterogeneous firm response to labor cost shocks can be explained by differences in governance or management practice, but is difficult to reconcile with the idea that competitive pressure is a substitute for governance quality.
\end{abstract}

JEL Classification: D24, G31, J24, J31, O14

Keywords: Firm productivity, capital investment, minimum wage policy

\footnotetext{
*University of Geneva, GSEM, Geneva Finance Research Institute, 42 Bd du Pont d'Arve, 1211 Genève 4 , Switzerland. Tel.: (++41) 22379 9581. E-mail: prof@haraldhau.com. Web page: http://www.haraldhau.com. ** Graduate Institute of International and Development Studies, Maison de la paix, Chemin Eugène-Rigot 2, 1202 Genève, Switzerland. Tel: +41 2290859 40. E-mail: yi.huang@graduateinstitute.ch.

*** Graduate Institute of International and Development Studies. E-mail: geweiwang@gmail.com.
} 


\section{Acknowledgments}

We thank seminar participants at the Graduate Institute, Geneva, and the Haas School of Business, UC Berkeley, the 18th NBER-CCER Conference in Peking, and the Fifth HKUST Summer Workshop in Macroeconomics for their comments on an earlier draft. In particular Jean-Louis Arcand, Matthias Efing, Michel Habib, Annette Vissing-Jørgensen, Adair Morse, Liugang Sheng, David Sraer, David Thesmar, Shang-Jin Wei and Michael Song Zheng provided valuable comments. We are especially grateful to Nicholas Bloom and John van Reenen for providing us with the survey data on management practices in Chinese firms. This research project benefited from a Sinergia Research Grant from the Swiss National Science Foundation (SNSF). 


\section{Introduction}

In the first decade of the new century, China's large manufacturing sector was subject to frequent minimum wage changes that varied greatly across regions - making China a unique laboratory for studying the effect of minimum wage shocks on firm behavior and productivity. During the period 2002-08, China's 2,867 counties and 333 cities implemented more than 17,000 changes in the local minimum wage, of which more than a quarter was larger than $20 \%$ as shown in Figure 1. Many of the most affected firms are in the manufacturing sector and produce tradeable products. Hence, any large local minimum wage increase represents an important competitive shock to the firm if its competitors in other locations or with a different wage structure do not face the same increase in labor costs. Firms experiencing a substantial labor cost increase should ceteris paribus reduce output and employment and lose market share. Yet, a more precarious competitive position can simultaneously facilitate firm restructuring in pursuit of higher productivity. The main contribution of this paper to analyze this endogenous productivity response among Chinese manufacturing firms. Did adverse cost shocks accelerate their productivity growth? And did other factors like firm ownership and management quality influence the endogenous response?

A "Darwinian" view of competition regards adverse cost shocks as an opportunity to restructure and reduce organizational slack. Substantial reorganization often requires a consensus among managers and the workforce and may be easier to reach under increased external pressure. ${ }^{1}$ Accordingly, a theoretical management literature argues that increased competitive pressure reduces agency problems and can even substitute for a performance contingent managerial pay incentives (Schmidt, 1997; Aghion, Dewatripont and Rey, 1999). In this Darwinian perspective, adverse competitive shocks can raise productivity because they align interests irrespective of the quality of management. The largest benefits to competitive shocks may even accrue to the firms with the worst ex ante agency problems if stronger external market/survival incentives can substitute for internal incentive practices.

An alternative "managerial" view emphasizes the importance of management quality for firm productivity. In a series of papers, Bloom, et al. (2010), and Bloom and van Reenen (2007, 2010), have documented the positive correlation between firm productivity and the quality of

\footnotetext{
${ }^{1}$ This view has been popularized by Michael Porter (1990).
} 
management practice within industries and across countries. This correlation could be the result of better managed firms responding more effectively to competitive challenges so that competitive shocks and management quality are complementary in their beneficial effects on productivity growth. Still, there is surprisingly little direct evidence that management quality indeed plays a key role for the evolution of firm productivity.

Like in most emerging markets, Chinese firms feature large heterogeneity in firm productivity, management practice, firm governance and corporate ownership. The coexistence of state-owned enterprises (SOEs), private Chinese-owned firms and foreign-owned firms supports this variation with considerably higher levels of management quality (and pay) observed in foreign owned firms as illustrated Figure 2. Adjusted for firm size and industry fixed effects, management practice in the three dimensions of (1) monitoring practices (the collection and processing of production information); (2) target-setting practices (the ability to set coherent, binding short- and long-term targets); and (3) incentive practices (merit-based pay, promotion, hiring, and firing) is on average $15 \%$ higher in privately owned firms and $25 \%$ higher in foreign owned firm compared to SOEs. Labor cost shocks caused by local minimum wage changes can function as a treatment effect to explore if and how different ownership types determine the endogenous productivity response within China's vast manufacturing sector.

Our analysis draws on both intertemporal and geographic (county-level) variation of Chinese minimum wages for the period 2002-08. In addition we take account of the heterogeneous exposure of firms to minimum wage shocks in a two-step procedure. First, we estimate the impact of increases in the minimum wage on a firm's average wage increase. Here we assume that firm exposure is a (non-linear) function of the distance of the average firm wage from the (prior) local minimum wage - proxying for the "utilization" of low-wage labor. Second, the reduced form regressions capture "treatment heterogeneity" by interacting the estimated firm-specific exposure with the observed local minimum wage increase. In addition, we allow the more exposed low-wage firms to differ from their industry peers with higher wages: We use dynamic panel regressions with firm fixed effects that account for any (time-invariant) omitted variable that could influence the firm-specific growth trend of any dependent variable.

Our empirical findings are threefold. In accordance with neoclassical firm theory, we find that (relative to their high-wage industry peers) low-wage firms accelerate their labor to capital substitution in the year of the local minimum wage increase. The effect on employment growth 
is clearly negative across firm types and extends to state-owned enterprises (SOEs). Yet, large and foreign-owned firms with a low average wage show the largest labor substitution effect in their response to the labor cost shock.

Second, adverse labor cost shocks due to increased minimum wages do not reduce relative output or capital input as predicted by neoclassical firm theory under constant productivity growth. The non-negative relative output growth reflects a relative increase in total factor productivity (TFP) for low cost firms in the year of the minimum wage increase. The endogenous productivity response of low-wage firms to adverse labor cost shocks is robust to different TFP measures. Moreover, the finding of accelerated TFP growth is concentrated in the bottom half of the intra-industry TFP distribution. The positive TFP response therefore represents a TFP "catch-up" effect.

Third, we explore the transmission channel for productivity improvements. We find that the productivity increase under minimum wage shocks is conditional on firm ownership: Private Chinese-owned firms and (even more so) foreign-owned firms show a strong response to the minimum wage shock, whereas SOEs do not. The Darwinian perspective that increased competitive pressure represents a remedy against managerial slack does not seem to be born out by this heterogeneous response. Similarly, efficiency wage theory is at odds with this finding because bottom-up incentive effects should not be conditional on firm ownership. Instead, variations in management practice appear to matter most: We extrapolate survey data about management practice in Chinese firms (Bloom, Mahajan, McKenzie and Roberts, 2010; Bloom and van Reenen, 2007, 2010) to the full firm sample and find that superior management practices, particularly in foreign-owned firms, can account for the heterogeneous productivity response to adverse labor cost shocks.

We subject these results to a variety of robustness tests. Our TFP measures are based on deflated firm revenues using industry-specific output deflators which may not reflect a firm's true output prices. This becomes a particular concern if higher minimum wages are passed through to higher product prices. To address this issue, we complement the TFP measures with (independently collected) export statistics from the Chinese custom authorities which report firm specific export quantities and prices separately. The custom data reveal that minimum wage shocks translate (again for private and foreign-owned firms only) into larger export quantities, but not into higher export prices. Accordingly, we argue that TFP mismeasurement due to 
incorrect product price deflators is unlikely to account for the evidence.

A second concern relates to survivorship bias. Particularly for small firms, our sample is unbalanced and sampling may ignore the less productive firms which have exited the market. We expect such a survivorship bias to be more pronounced among small firms, whereas the strongest endogenous productivity response is found among large firms for which our sample is most balanced. We also re-estimate the effects for a balanced subsample of firms which report without interruption and find qualitatively similar results.

We also explore if local minimum wage changes respond to anticipated productivity gains of local firms. While local government may adjust the minimum wage policy to aggregate local economic conditions, it seems unlikely that they would do so in response of a relative productivity growth between private/foreign firms and SOEs - required to explain the difference in correlation by ownership type under reverse causality. Additional regressions reported in the Appendix indeed show no evidence that performance differences between SOEs and other firms matter for the minimum wage setting. ${ }^{2}$ Local authorities may also lack information on foreign firm productivity, and could at best respond to the stock market valuations of local listed companies. However, stock market valuations of listed local companies (under private or foreign ownership) again do not predict minimum wage changes. ${ }^{3}$

\section{Related Literature}

The role of competition remains a key topic in the research agenda on the determinants of growth (Syverson, 2011). Unfortunately, the level of competition is often inextricably entangled with the technological progress itself so that competitive shocks are rarely exogenous to productivity growth. The minimum wage shocks to the Chinese manufacturing sector represent a source of competitive pressure which is regulatory in nature, precisely identified in terms of geographic scope, and in their exact timing largely exogenous to the firm-specific productivity process.

Trade agreements represent a different regulatory shock which can exogenously intensify

\footnotetext{
${ }^{2}$ Political economy considerations suggest that local authorities could be more sensitive to the performance of SOEs so that the reverse causality channel is more plausible for SOEs. Yet precisely for SOEs we find no correlation between TFP growth and the minimum wage increases.

${ }^{3}$ Note also that foreign firms account for no more than $28 \%$ of manufacturing employment over the period 2002-08.
} 
competition and has therefore attracted considerable research interest. Bernard, Jensen and Schott (2006) study the response of U.S. manufacturing industries and plants and show that declining trade barriers tend to accelerated productivity growth. Lileeva and Trefler (2010) look at the response of Canadian plants to U.S. tariff cuts and finds a positive productivity and innovation effect of improved market access. ${ }^{4}$

An important policy debate centers on the response of U.S. and European firms to China's integrations into the global supply chain. Bena and Simintzi (2016) find that access to cheap labor following the 1999 U.S.-China trade agreement lowers U.S. firm investment in (labor substituting) process innovation and reduces the corresponding patent production. Similar negative effects on U.S. firm investment and patenting are reported by Autor et al. (2016), whereas Bloom, Draca and van Reenen (2015) find that firms across 12 European countries innovated more when facing intensifying product market competition. Our paper is concerned with labor cost shocks within China's vast manufacturing sector. Unlike the slow import penetration process affecting non-Chinese firms, the direct labor cost shocks originating in Chinese minimum wage regulation can be dated very precisely.

Our most important finding concerns the endogenous productivity response to higher minimum wages by Chinese firms facing higher labor costs. We highlight that this productivity acceleration is stronger for low initial levels of productivity and contingent on firm ownership. This rules out certain transmission channels, like efficiency wages, as the source of the productivity gain. If higher wages simply improve the quality of labor supply (i.e. the non-contractable effort level) or reduce labor turnover, we expect to find more uniform productivity gains across firms of any ownership type. Our evidence points instead to the role of firm ownership and in particular management practice (Bloom and Van Reenen, 2010) as the explanation for differences in firm adaptability. It also points to a general weakness of the state-owned sector to cope with productivity challenges (Song, Storesletten and Zilibotti, 2011; Zhu, Brandt and Tombe, 2013; Zhu and Tombe, 2015; Song and Wu, 2015; Hsieh and Song, 2015).

Labor economics mostly focuses on the direct employment effect of minimum wage changes. Recent studies including Brown (1999), Meer and West (2013), Neumark, Salas, and Wascher (2014), and Dube, Lester, and Reich (2015) do not arrives at any clear consensus view on the

\footnotetext{
${ }^{4}$ For a discussion of financial firm performance after tariff changes see also Boven III, Frésard. and Taillard (2015) and Frésard and Valta (2016).
} 
employment effect. Firm-level evidence by Katz and Krueger (1992), Card and Krueger (1994), and Neumark and Wascher (2008) shows negligible or positive employment responses in U.S. data. $^{5}$ By contrast, the considerably higher minimum wage variation in the Chinese manufacturing sector, combined with a higher share of low wage workers, create a more propitious setting for negative employment effects. Wang and Gunderson (2012), Fang and Lin (2013), Jia (2014), and Huang, Loungani, and Wang (2014) all find negative employment effects for at least parts of the Chinese labor force. We contribute to the existing evidence based on improved identification techniques that account for the heterogeneous exposure of Chinese manufacturing firms to minimum wage increases.

Macroeconomic research has highlighted the role of productivity dispersion for a country's aggregate productivity. In particular, emerging countries feature large productivity gaps between their most and least efficient firms (Hsieh and Klenow, 2009, 2014; Bloom, et al., 2010; Foster, Haltiwanger, and Krizan, 2010; Hsieh and Ossa, 2011; Syverson, 2011), which may pull down overall aggregate industry productivity. Minimum wage policies in China appear to have lowered such productivity dispersion at least among private-owned firms. Related work by Haepp and Lin (2015) also finds positive capital investment effects in private firms following a minimum wage increase; however they do not examine overall firm productivity.

Understanding the determinants of productivity growth has significance beyond emerging markets: Developed countries have been characterized by decreasing (labor) productivity growth over the last decades, with wages at the low end of the pay scale experiencing hardly any real wage increases. While the orthodox view considers labor productivity as the cause of real wage growth, evidence on the endogeneity of firm productivity to labor costs suggests that the reverse causality could also be an important channel (The Economist, 2016; Pessoa and Van Reenen, 2013). An abundant supply of low-wage labor could retard the adoption of new capita-intensive technologies and contribute to a productivity slowdown (Bena and Simintzi, 2016).

Finally, we can relate our evidence to discussions on international competitiveness. An appreciating currency is sometimes portrayed as forcing domestic firms to continuously increase

\footnotetext{
${ }^{5}$ We note that endogenous productivity effects could make the employment response of minimum wage increases industry-specific: A productivity effect can potentially dominate any input factor (labor) substitution effect whenever the scope for factor substitution in a given industry is limited - thus accounting for some of the ambiguous or insignificant employment effects found in the literature.
} 
firm productivity (Porter, 1990; Boltho, 1998). However the evidence for such a currency channel remains elusive because of plausible reverse causality from increased productivity to an appreciating currency, known as the Harrod-Balassa-Samuelson effect. ${ }^{6}$ By contrast, the labor cost shocks in our study originate in (more) exogenous policy measures and therefore allow for a better causal inference on the same economic mechanism between an adverse competitive shock and the productivity response of the firm.

The following section provides a simple theoretical framework and motivates the various hypotheses. Section 4 discusses the data and Section 5 identifies the impact of minimum wage increases on average firm wages. The evidence based on reduced-form estimation is presented in Section 6. We offer various robustness tests in Section 7 and Section 8 concludes.

\section{A Neoclassical Model with Labor Heterogeneity}

Average firm wages vary across firms within the same industry and this partially reflects differences in average labor quality. In a competitive labor market higher individual labor productivity translates into a higher wage. This allows for the coexistence of firms with low- and high-skill labor, where the high-skill firm employs fewer workers at a higher average wage. But such firm differences in the wage structure imply that a minimum wage increase has heterogeneous effects on the labor costs of individual firms even if they are subject to the same regulatory change.

To explore this aspect in more detail, the following sections outline a simple neoclassical model of labor input heterogeneity. A low- and high-wage firm face the same minimum wage increase, but adjust differently to the asymmetric labor cost shock. First, we characterize the profit optimizing input and output response of both firms in two propositions that abstract from any endogenous productivity response of the firm. In a second step, we extends the model to allow for a (differential) TFP effect in reaction to higher labor costs. Here, we also discuss different transmission channels from minimum wage increases to productivity improvements.

\footnotetext{
${ }^{6}$ Plausible exceptions to this argument are unexpected changes in the exchange rate regime, like the appreciation of the Swiss franc on January 15, 2015. For evidence on this event see Efing et al. (2016).
} 


\subsection{Minimum Wage Shocks under Monopolistic Competition}

Consider a two-period model in which two monopolistic firms, $s \in\{L, H\}$, produce goods $L$ and $H$, respectively. Let $H$ denote the good produced with high-skilled labor at high average wages, whereas $L$ is produced mostly with low-skill labor at a low average firm wage. The two firms are described by a Cobb-Douglas production function in value added output. They combine inputs in capital $K$ and labor $L$ to generate value added output $Y_{s}=$ Gross Revenue $/ p_{Y}-$ Cost Intermediate Goods $/ p_{X}$ as the difference between gross revenue (deflated by the industry price index $p_{Y}$ ) and the cost of intermediate good inputs (deflated by the intermediate goods price index $p_{X}$ ). Formally, the two production functions are given by

$$
Y_{L}=A_{L} K_{L}^{\alpha} L_{L}^{\beta} \quad \text { and } \quad Y_{H}=A_{H} K_{H}^{\alpha} L_{H}^{\beta},
$$

where the labor input $L$ is the product of average labor quality $Q$ and labor quantity $N$ (employment) according to

$$
L_{L}=Q_{L} N_{L} \quad \text { and } \quad L_{H}=Q_{H} N_{H}
$$

respectively. In the absence of any minimum wage restrictions in the first period, average labor quality (over the distribution of all firm employees) is measured by the average wage with $Q_{L}=w_{L}<w_{H}=Q_{H}$ and labor quantity by the number of firm employees. While average labor quality and quantity are substitutes in the long run, we assume that the average labor quality $Q$ is a fixed factor that cannot be changed in the short run. ${ }^{7}$ A binding minimum wage introduced in period 2 drives a wedge between labor quality and the average wage. Only employment $N$ and the capital stock $K$ can adjust in period 2. For simplicity we also assume constant returns to scale with $\alpha+\beta=1$ and that both firms face the same cost of capital and the same factor price for the intermediate good. The asymmetric use of low-skill labor by the two firms implies an unequal exposure to a minimum wage increase $\Delta \ln w^{\text {min }}>0$. Firm, $L$ with its greater reliance on low-skill labor, suffers a larger increase in its average (log) wage

\footnotetext{
${ }^{7}$ Adjustment costs imply that substitution of a large share of the workforce (embodying $Q$ ) is neither feasible nor cost-effective in the short run.
} 
$\Delta \ln w^{L}$ (without a corresponding increase in labor quality) than firm $H$, with marginal effects

$$
\frac{\Delta \ln w_{L}}{\Delta \ln w^{\min }}>\frac{\Delta \ln w_{H}}{\Delta \ln w^{\min }}
$$

Such asymmetric exposure of firms implies that the effect of minimum wage shocks is also heterogeneous and that an econometric identification procedure should account for this heterogeneity. Consider a unimodal distribution of employee wages (within a firm) and assume it differs across firms only by its mean, but not its shape. Under a higher minimum wage, the wage distribution becomes left-censored at the minimum wage and a certain share of worker is employed at the minimum wage itself and above marginal labor productivity. It follows that the more a firm's average wage $w_{s}$ approaches the minimum wage $w^{\text {min }}$, the larger the share of employees affected by any new minimum wage increase and the larger the increases the firm's average wage without a commensurate increase in the "sticky" labor quality. ${ }^{8}$ To capture this relationship between the average firm wage increase and a minimum wage hike, we can define an impact function $(I F)$ as

$$
I F\left(w_{s} / w^{\min }\right)=\frac{\Delta \ln w_{s}\left(w_{s} / w^{\min }\right)}{\Delta \ln w^{\min }} \quad \text { with } I F^{\prime}<0
$$

In the empirical part, we estimate the impact function using the functional form $I F\left(w_{s} / w^{\min }\right)=$ $\lambda\left(w_{s} / w^{\text {min }}\right)^{-(k+1)}$, where the parameter $\lambda>0$ determines the strength of the average wage effect and $k>0$ governs its convexity. Correctly characterizing the impact function allows for a better identification of the effective firm exposure to any given minimum wage increase.

The demand side of the model assumes a representative consumer with a utility function given (in each period) by

$$
U=\left[C_{L}^{\frac{\theta-1}{\theta}}+C_{H}^{\frac{\theta-1}{\theta}}\right]^{\frac{\theta}{\theta-1}}
$$

subject to a period budget constraint $C_{L} p_{L}+C_{H} p_{H}=B$. We can normalize the price of good $H$ as $p_{H}=1$. The parameter $\theta>1$ denotes the marginal rate of substitution. For $\theta \rightarrow \infty$ the two products become perfect substitutes and the market converges to the benchmark of perfect

\footnotetext{
${ }^{8}$ In the special case that the firm faces no frictions in firing all employees with labor productivity below the minimum wage and replace them with employees of higher quality, no competitive disadvantage results. But as convincingly argued by Long and Yang (2016), even Chinese private firms face considerable labor market rigidities in the short run.
} 
competition.

The model assumes a predetermined distribution of labor quality for each firm and ignores adjustment costs other than a limited (short-run) ability to replace low wage workers of low marginal labor productivity. The dynamic firm problem will generally differ from the myopic solution presented below. Firms could manage their labor pool dynamically in order to limit any future wedge between the expected minimum wage and the productivity of low-wage workers. But in practice, firms might find it hard to predict the evolution of the local minimum wage relative to the labor productivity growth for low wage workers. Dynamic consideration could therefore be of secondary importance and only attenuate the contemporaneous relationship derived for the myopic case in the next section.

\subsection{Solution}

Solving this simple neoclassical firm model (with labor rigidity) is straightforward and the details are provided in Appendix A. Here we summarize the solution in two propositions. The (log) change of any variable $\ln X$ from period 1 to period 2 is denoted by $\Delta \ln X=\ln X_{t}-\ln X_{t-1}$ and the minimum wage constraint is effective only in the second period after a $(\log )$ increase $\Delta \ln w^{\min }>0$.

\section{Proposition 1: Optimal Adjustment of Capital to Labor Input Ratios}

Assume two firms $L$ and $H$ with the Cobb-Douglas production function specified in equations (1),(2) and an asymmetric firm exposure of their average wage to a minimum wage change given by $I F_{L}>I F_{H}$, respectively. For a minimum wage change $\Delta \ln w^{\mathrm{min}}$, the profit maximizing adjustment of their relative capital to labor ratios follows as

$$
\Delta \ln \frac{K_{L}}{N_{L}}-\Delta \ln \frac{K_{H}}{N_{H}}=\Delta \ln w_{L}-\Delta \ln w_{H} \approx\left[I F_{L}-I F_{H}\right] \Delta \ln w^{\min }
$$

According to Proposition 1, relative changes in the two-factor input ratios do not depend on any of the technology parameters of the Cobb-Douglas production functions $\alpha$, $\beta$, or $\gamma$. We also highlight that the relative input ratios are invariant to any change in the productivity parameters $\Delta \ln A_{L}$ and $\Delta \ln A_{H}$ of firms $L$ and $H$, respectively. Neither does the relative 
factor ratio response of the two firms depend on the elasticity of substitution $\theta$ of their output and therefore on the degree of product competition. Only the relative exposure of the firm to the minimum wage change captured by the term $I F_{L}-I F_{H}$ matters for the optimal change in factor input ratios. All this suggests a simple reduced form regression with a firm's (log) capital share as the dependent variable and the interaction of a firm's exposure $I F$ and the (log) minimum wage change $\Delta \ln w^{\text {min }}$ as the explanatory variable.

But we also obtain closed form expressions for the other endogenous variables summarized as follows:

\section{Proposition 2: Optimal Output and Factor Response under Hetero- geneous Labor Quality}

Faced with an increase in their average wage by $I F_{L} \times \Delta \ln w^{\min }$ and $I F_{H} \times \Delta \ln w^{\min }$ due to the minimum wage increase, respectively, firms $L$ and $H$ optimally adjust their (relative) output $(Y)$, capital input $(K)$, employment input $(N)$ and firm profits (П) according to

$$
\begin{aligned}
\Delta \ln Y_{L}-\Delta \ln Y_{H} & =-\theta \Delta \ln \frac{p_{L}}{p_{H}} \\
\Delta \ln K_{L}-\Delta \ln K_{H} & =-(\theta-1) \Delta \ln \frac{p_{L}}{p_{H}} \\
\Delta \ln N_{L}-\Delta \ln N_{H} & =-(\theta-1) \Delta \ln \frac{p_{L}}{p_{H}}-\left[I F_{L}-I F_{H}\right] \Delta \ln w^{\min } \\
\Delta \ln \Pi_{L}-\Delta \ln \Pi_{H} & =-(\theta-1) \Delta \ln \frac{p_{L}}{p_{H}},
\end{aligned}
$$

and where changes of the relative (log) output prices $(p)$ follows as

$$
\Delta \ln \frac{p_{L}}{p_{H}}=\Delta \ln A_{H}-\Delta \ln A_{L}+(1-\alpha)\left[I F_{L}-I F_{H}\right] \Delta \ln w^{\min }
$$

Proposition 2 highlights two distinct channels through which the minimum wage shock affects relative firm outputs, factor inputs and firm profits. The relative employment change $\Delta \ln N_{L}-\Delta \ln N_{H}$ in Eq. (9) is inversely proportional to the respective relative increase of the average wage given by $\left[I F_{L}-I F_{H}\right] \Delta \ln w^{\text {min }}$. A second effect concerns the role of the minimum wage change for the competitive position of each firm captured by the change in relative product prices $\Delta \ln \frac{p_{L}}{p_{H}}$. Optimal monopolistic output pricing implies an adjustment of the relative 
product prices in proportion to (i) the product of the labor share $(1-\alpha)$ and exogenous relative average wage increase $\left[I F_{L}-I F_{H}\right] \Delta \ln w^{\min }$ and (ii) the relative changes $\Delta \ln A_{H}-\Delta \ln A_{L}$ in firm productivity. In the absence of any endogenous productivity response to changing labor costs, the competitive effect on relative output and all factor inputs simplifies to the single term $-(\theta-1) \Delta \ln \frac{p_{L}}{p_{H}}$ in Eq. (9). The larger the product price increase of firm $L$ relative to firm $H$, the larger the loss in market share of the low-wage firm becomes. More product market competition represented by a higher $\theta$ aggravates the relative production decrease of low-wage firm $L$.

These results highlight the role of heterogeneous exposure under minimum wage changes. Low wage firms suffer a negative competitive shock in proportion to the relative average wage changes $\left[I F_{L}-I F_{H}\right] \Delta \ln w^{\mathrm{min}}$. Neoclassical investment theory under employment rigidities predicts a relative decrease in firm output and capital input given by $-(\theta-1)(1-$ $\alpha)\left[I F_{L}-I F_{H}\right] \Delta w^{\mathrm{min}}$. The relative employment decrease is predicted to be even larger at $-[1+(\theta-1)](1-\alpha)\left[I F_{L}-I F_{H}\right] \Delta w^{\mathrm{min}}$. Next we show how these results are partly overturned under an endogenous productivity response by low-wage firms.

\subsection{Endogenous Productivity Response and its Channels}

Propositions 1 and 2 characterize the optimal firm response under constant relative factor productivity, that is $\Delta \ln A_{H}-\Delta \ln A_{L}=0$. Yet, a minimum wage shock could trigger an endogenous firm response that changes the (relative) total factor productivity of the low-wage firm.

We can distinguish two theories that can rationalize such a differential productivity effect under adverse competitive shocks. First, the theory of efficiency wages assumes that high wages can increase labor productivity because higher pay can mobilize a higher level of labor productivity in a way that the labor contact itself cannot. A higher wages increase any potential employee loss related to contract termination and as a consequence the opportunity cost of shirking increases. It might also reduce the cost of labor turnover which tends to be high among low skill manufacturing workers. Positive productivity effects of minimum wage increases rely on an inefficiently low prior wage and represent an improvement in labor productivity at the bottom of the organizational hierarchy. Importantly, such productivity gains should be 
available independently of a firm's governance, and in particular should not be contingent on firm ownership.

Second, an endogenous response could result from managerial incentives if private payoffs of managers are a concave function of relative changes in firm profitability. Performance monitoring mechanisms can benchmark the firm performance against that of the competitor and sanction relative underperformance, for example with an increased likelihood of firing the CEO or the top management team. Assume manager utility in the low-wage firm is captured by the function

$$
U_{L}=\gamma \min \left(\Delta \pi_{L}-\Delta \pi_{H}, 0\right)
$$

where $\Delta \pi_{L}-\Delta \pi_{H}$ denotes the change in the (log) profit difference between the two firms, which can be conveniently expressed as

$$
\Delta \pi_{L}-\Delta \pi_{H}=(\theta-1)\left[\Delta \ln A_{L}-\Delta \ln A_{H}\right]+(\theta-1)(1-\alpha) \ln \frac{1+I F_{H} \Delta w^{\min }}{1+I F_{L} \Delta w^{\min }}
$$

If managers face a (strictly) increasing, continuous private marginal cost function $P M C\left(\Delta a_{L}\right)$ for an improvement in (log) firm productivity by $\Delta a_{L}=\Delta \ln A_{L} \geq 0$, we can determine the effort level of the managers by the first-order condition

$$
\frac{d U_{L}}{d \Delta a_{L}}=P M C\left(\Delta a_{L}\right)
$$

The optimal endogenous response to the adverse shock follows as

$$
\Delta a_{L}=\left\{\begin{array}{ll}
0 & \text { if } \Delta \pi_{L}>\Delta \pi_{H} \\
\min \left\{P M C^{-1}[\gamma(\theta-1)], \Delta \bar{a}_{L}\right\} \geq 0 & \text { if } \Delta \pi_{L} \leq \Delta \pi_{H}
\end{array},\right.
$$

where $P M C^{-1}$ denotes the inverse of the private marginal cost, $\gamma(\theta-1)$ represents the marginal private benefit to the manager of more $\log$ productivity whenever $\Delta \pi_{L} \leq \Delta \pi_{H}$, and $\Delta \bar{a}_{L} \geq 0$ the maximum productivity increase until $\Delta \pi_{L}=\Delta \pi_{H}$. This example illustrates how management in the low-wage firm might respond to a relative profit shortfall after the minimum wage shock and endogenously increase firm productivity.

Both channels could explain by increased competitive pressure due to adverse cost shocks cause an endogenous productivity response summarized in the following hypothesis: 


\section{Hypothesis 1: Endogenous Response to Adverse Cost Shocks}

Adverse minimum wage shocks can trigger an increase in a firm's total factor productivity, where the affected low-wage firm $(L)$ increases firm productivity by more than its industry peer with higher wages $(H)$, that is $(\eta>0)$

$$
\Delta \ln A_{L}-\Delta \ln A_{H}=\eta\left[I F_{L}-I F_{H}\right] \Delta \ln w^{\min }>0 .
$$

Any endogenous productivity response by low-wage firms to adverse minimum wage shocks will lower the output and factor input reduction predicted in Proposition 2. Depending on the magnitude of the productivity response embodied in the parameter $\eta>0$, the optimal relative product price change can flip signs and become negative, because

$$
\Delta \ln \frac{p_{L}}{p_{H}}=(1-\alpha-\eta)\left[I F_{L}-I F_{H}\right] \Delta \ln w^{\min }
$$

Under a strong endogenous productivity response by low-wage firms to adverse minimum wage shocks, their product output, factor inputs and firm profitability can keep up with that of the high wage firm, provided that $1-\alpha-\eta \approx 0$. Generally, we expect to see a positive relative TFP growth for these low-wage firms as stated in hypothesis 1.

\subsection{Firm Differences in the Endogenous Response}

Recent work by Bloom and Reenen $(2007,2010)$ has emphasized the role of management practice for firm productivity and related large TFP differences between firms from developed and developing countries to the quality of firm management. As illustrated in Figure 2, differences in management quality are particularly pronounced between foreign owned firm and SOEs. Different monitoring practices are one element of this difference, which can include performance benchmarking against competing firms analogous to Eq. (12).

Relative performance monitoring may be a more effective management tool, but also requires more information on competitors and therefore not all firm are able to implement it to the same degree. High information hurtles for monitoring systems can lead to more firm heterogeneity in the endogenous response to competitive shocks. We summarize this firm type contingency of the endogenous response in hypothesis 2 : 


\section{Hypothesis 2: Firm Type Contingent Endogenous Response}

The quality of management in general and performance monitor in particular may condition the endogenous firm response to adverse competitive shocks. Relative to SOEs, private-owned and particularly foreign-owned firms could feature (on average) a higher degree of endogenous response $\eta(i)$. Therefore,

$$
\Delta \ln A_{L}-\Delta \ln A_{H}=\eta(i)\left[I F_{L}-I F_{H}\right] \Delta \ln w^{\min }>0 .
$$

with $\eta($ Foreign $)>\eta($ Private $)>\eta(\mathrm{SOE}) \geq 0$.

To test hypothesis 2 , we introduce ownership dummy variables which are then interacted with the firm specific minimum wage shock $I F_{s} \times \Delta \ln w^{\min }$. Section 6.5 extends the analysis by using data on management practice in Chinese firms.

\section{Data}

\subsection{Minimum Wage Policy in China}

China's minimum wage policy dates back to July 1994, when a new labor law stipulated a system of minimum wages. According to Article 48 of the then labor law, firms in the formal sector were required to comply with the minimum wage set at the local level. Provincial governments were authorized to set the local minimum wage, which could vary across cities and even counties within the same province. City- and county-level authorities could negotiate local minimum wages with their respective provincial authorities (Casale and Zhu, 2013). Local governments therefore obtained substantial influence over the particular minimum wage policy applicable in their city or county; higher authorities would mostly review these policies and take responsibility for their enforcement. Enforcement of minimum wage policies was improved over time. After 2003, the frequency of minimum wage changes increased in a period of rapid industrial growth.

In March 2004, the Ministry of Labor and Social Security initiated a policy reform to achieve a more uniform implementation of minimum wage policies without questioning local autonomy in the rate-setting process. The reform measures emphasized (1) an explicit extension 
of coverage to town/village enterprises and self-employed businesses; (2) a new standard for hourly minimum wages; (3) an increase in penalty for non-compliant enterprises from $20-100 \%$ to $100-500 \%$ of the wage shortfall; and (4) more frequent minimum-wage adjustment (at least once every two years). Local departments of labor had to exercise supervision within the scope of each hierarchical administration and evidence suggests that compliance with minimum wage standards became much more uniform (Su and Wang, 2014).

The minimum wage data used in this paper comes from the Ministry of Human Resources and Social Security (MOHRSS) and the China Academy of Labor and Social Security; it covers the period 1996-2012. To match minimum wage data to the annual reporting frequency of the firm data, we calculate (average) annual minimum wages for each county/city whenever minimum wage adjustments occur during the calendar year. The distribution of (annual) minimum wage changes is depicted in Figure 1.

For much of the analysis, we only use data for the period 2000-08, because reliable firm level survey data starts only in 2000 and stop in 2008. The Chinese statistical authorities discontinued the release of data from the Annual Survey of Industrial Firms (ASIF) in 2009. Table 1, Panel A reports summary statistics on (nominal) minimum wage changes expressed in $\log$ changes $\Delta \ln w_{t}^{\min }=\ln w_{t}^{\min }-\ln w_{t-1}^{\min }$. The average annual increase in the minimum wage is high at $2.8 \%$ per year with an extremely large (cross-sectional) standard deviation of approximately $10 \%$ in every sample year from 2002 to 2008 . China is exceptional in both the magnitude of minimum wage changes as its enormous regional heterogeneity.

Generally, minimum wage changes occurred less frequently before 2003, but became more frequent thereafter. Huang, Loungani, and Wang (2014) explore the determinants of minimum wage change and find very little evidence that economic conditions, like local growth or unemployment, have explanatory value in predicting minimum wage changes. ${ }^{9}$ In particular, the timing of the a minimum wage change may largely be determined by internal party politics, which can be considered an exogenous factor for the purpose of this study.

\footnotetext{
${ }^{9}$ The level of the minimum wage is more strongly correlated with the local price levels, however our analysis considers firm adjustment to largely unpredictable minimum wage changes.
} 


\subsection{Chinese Firm Data}

The firm-level data in our study comes from the Annual Survey of Industrial Firms (ASIF), also known as the Chinese Industrial Enterprise Database (CIED). According to this survey, "large-scale" industrial firms file detailed reports every year to their local Bureau of Statistics. The National Bureau of Statistics (NBS) then aggregates the data to produce key statistics for industrial output and employment and publishes them in the China Statistical Yearbook. Our sample spans the period 2002-08 and other than in 2008 it contains the same number of observations used by NBS. The firm sampling covers the full sample of large firms (those with more than 1,000 employees) and a large proportion of medium firms (between 200 and 1,000 employees), whereas coverage is more incomplete for small firms with fewer than 200 employees. The survey covers all industrial sectors and the mining sector. It accounts for roughly $88 \%$ of the national industrial output. In 2009, the ASIF was discontinued for one year, so that there are no reliable firm survey data available for that year. No official reason was provided, but speculations circulated that the statistical authorities tried to obstruct any investor inference about a recession in the Chinese manufacturing sector.

Reporting errors in the survey require a stringent filtering process for data errors. The various filters employed are documented in the data appendix. We filter out firm observations with abnormal growth rates of real minimum wages and exclude firm observations for which critical firm variables are in the $1 \%$ upper and lower tail of the yearly distribution. Table 1, Panel B provides the summary statistics on the full firm sample, which (after the filtering procedure) contains 1,192, 144 firm-year observations. Panels C, D, and E provide a breakdown of the sample by ownership type with 104, 709 firm years observations for state-owned enterprises (SOEs), 825, 907 observations for privately owned firms (in full Chinese ownership) and 261, 528 firm years for (fully or partially) foreign owned firms. In addition, we sort firms by their total factor productivity into two equal-sized groups of low-and high-TFP firms based on a productivity ranking at the beginning of the sample (or when a firm is first observed). As minimum wage changes pose the largest competitive challenge to firms with below median

productivity, it is interesting to examine the heterogeneity in firm adjustment along the productivity dimension. Moreover, low productivity firms might also feature the largest potential for productivity improvements. Table 1, Panels F and G provide the summary statistics for 
low-and high-TFP firms, respectively. The summary statistics reported in Table 1 concern the (log) annual change in the capital to labor ratio $\Delta \ln (K / N)$, the (log) annual change in value added output $\Delta \ln Y$, the $(\log )$ employment change $\Delta \ln N$, the log change in the capital stock $\Delta \ln K$, and two measures of total factor productivity growth denoted $\Delta \ln (A 1)$ and $\Delta \ln (A 2)$, respectively. Value added output, capital and productivity are measured in real terms and deflated by the appropriate industry or intermediate input price indices.

Average (value added) output, capital, and labor growth differ by firm size. The largest output growth is found for privately owned firms with an average annual (log) growth of $19.4 \%$, followed by foreign owned firms at $15.1 \%$ and SOEs with only $8.8 \%$. Similarly, annual productivity growth is largest for privately owned firms (at $13.3 \%$ and $13.5 \%$, for $\Delta \ln (A 1)$ and $\Delta \ln (A 2)$, respectively), followed by foreign owned firms (at 10.3\% and 10.4\%) and SOEs (at $9.4 \%$ and $9.5 \%$ ). Correspondingly, the capital intensity, as measured by the (log) capital to labor ratio $\ln (K / N)$, grows faster for privately owned firms at $10.7 \%$ compared with only $5.6 \%$ and $5.3 \%$ for foreign owned firm and SOEs, respectively.

One shortcoming of the Chinese Industrial Enterprise Database (CIED) is a lack of firmspecific output price deflators. As a consequence we can only impute production output and TFP growth based on the industry output deflators. Heterogeneous firm exposure to minimum wage shocks in combination with wage pass-through to product prices may raise concerns that the industry price deflator could underestimate firm-specific price inflation and arrive at overestimated output and TFP changes precisely for those firms that experience the largest minimum wage increases. To explore this measurement bias, we use Chinese custom data that report value-based and quantity-based measures for exporting firms, separately. The change in the (log) value of exported output $\left(\Delta \ln E x p \_\right.$Value) can be decomposed into a (log) volume change $\left(\Delta \ln E x p \_\right.$Volume $)$and a change in log prices $\left(\Delta \ln E x p \_\right.$Price) at the firm level for exported output with summary statistics provided in Table 1, Panel H. The average (nominal) annual export growth was $30.9 \%$ in volume terms and $24.1 \%$ in value terms for the period 2000-08. 


\section{Identification of Minimum Wage Exposure}

A minimum wage increase should primarily affect firms with numerous employees at or near the current minimum wage. Unfortunately, data for the entire distribution of employee wages at the firm level are not available for Chinese firms. Instead, we use the average firm wage $w_{s}$ as a proxy for the percentage of employees likely to be affected by a minimum wage increase. In particular, we assume that the ratio $w^{\mathrm{min}} / w_{s}$ of the local minimum wage and the firm's average wage (both measured in year $t-1$ ) determines the impact of any minimum wage increase on average firm wages. The corresponding (non-linear) relationship can be estimated directly using the firm data. Formally, we capture the elasticity of average firm wages to minimum wage changes by the convex (impact) function $I F_{s}=\lambda\left(w_{s} / w^{\min }\right)^{-(k+1)}$, where the parameter $k$ governs the convexity of the function.

In order to estimate the convexity parameter $k$ as precisely as possible, it helpful to estimate $k$ for level changes in the minimum wage $\Delta w^{\text {min }}$ and firm wages $\Delta w_{s}$ rather than log changes. This reduces the convexity of the impact function by one unit from $k+1$ to $k$, because

$$
\frac{d \ln w_{s}}{d \ln w^{\min }}=\frac{w^{\min }}{w_{s}} \frac{d w_{s}}{d w^{\min }}=\frac{w^{\min }}{w_{s}} I F_{s}(k)=I F_{s}(k+1)
$$

In order to obtain the implied impact function for log changes, we simply increase the level

estimate $\widehat{k}$ to the corresponding changes $\widehat{k}+1$ for the impact function in log terms.

Next, we decompose the annual (log) firm wage change $\Delta \ln w_{s}$ into three terms: (1) the interaction term $I F_{s} \times \Delta \ln w^{\text {min }}$ between the impact factor and the minimum wage change characterizing the relatively higher average wage change for low wage firms; (2) the trend growth proportional to the impact factor $I F_{s}$ for all low wage firms; and finally (3) the general wage inflation proportional to the minimum wage change $\Delta \ln w^{\text {min }}$ affecting all firms equally. Formally, the panel specification becomes

$$
\Delta \ln w_{s}=\alpha+\beta\left[I F_{s} \times \Delta \ln w^{\min }\right]+\gamma I F_{s}+\delta \Delta \ln w^{\min }+\mu_{I n d \times Y e a r}+\nu_{s}+\epsilon_{s, t}
$$

where $\mu_{\text {Ind } \times Y \text { ear }}$ denotes interacted industry and time effects and $\nu_{s}$ a firm fixed effect.

Before we estimate the above equation in log changes, we first estimate it in level changes where $\Delta \ln w_{s}$ and $\Delta \ln w^{\text {min }}$ are replaced by $\Delta w_{s}$ and $\Delta w^{\text {min }}$, respectively. Table 2 , Columns 
(1), (4), and (7) report estimation results for (absolute) firm wage changes and minimum wage changes for each firm size group, where small firms have less than 200 employees, medium size firms between 200 and 1,000 employees and larger firm more than 1,000 employees, respectively. A maximum likelihood-based non-linear least square (NLLS) estimation is used to infer the convexity parameter $k$ separately for the sample of small, medium, and large firms. The three estimated parameters are relatively similar and statistically highly significant. The convexity parameter $k$ is 0.373 for small firms compared to 0.396 and 0.361 for medium and large firms, respectively. A parameter of 0.37 implies that a low-wage firm facing a minimum wage of $80 \%$ of its average wage will be exposed $67 \%$ more (in absolute terms) to any minimum wage increase $\left[(0.8)^{0.37} /(0.2)^{0.37}=1.67\right]$ compared to a high-wage firm for which the minimum wage represents only $20 \%$ of its average wage. Expressed in percentage terms relative to the firm wage, minimum wage impact is 6.68 times larger $\left[(0.8)^{1.37} /(0.2)^{1.37}=6.68\right]$ for the low-wage firm. This underlines the significant heterogeneity of exposure to minimum wage changes across firms.

The panel regressions in Columns (2)-(3), (5)-(6), and (8)-(9) of Table 2 repeat the same specification in log terms, where the dependent variable is now the log average firm wage growth $\Delta \ln w_{s}$ and the minimum wage change is also expressed in log changes $\Delta \ln w^{\min }$. In these and all following regressions we infer the corresponding convexity parameters directly from the level regressions as $k+1=1.373,1.396$, and 1.361 because the log transformation increases the convexity of the impact function by one unit from $I F_{s}(k)$ to $I F_{s}(k+1)$.

The panel regressions in Columns (3), (6), and (9) feature firm fixed effects and thus allow for different growth trends of individual firm wages. Inclusion of firm fixed effects implies that the economic and statistical significance of the interaction term $\left[I F_{s} \times \Delta \ln w^{\min }\right]$ increases further. In Column (3), a coefficient estimate $\widehat{\beta}=1.923$ implies that for a $22 \%$ increase in the minimum wage $\left[\Delta \ln \left(w^{\min }\right)=0.2\right]$, a small low-wage firm at the $10 \%$ wage quantile $\left(w_{s} / w^{\min }=1.409\right)$ of the wage distribution increases its $(\log )$ average wage $\ln w_{s}$ by $20.7 \%\left[=1.923 \times(1.409)^{-1.373} \times\right.$ $0.2-0.166 \times 0.2]$ compared to only $1.3 \%\left[=1.923 \times(4.683)^{-1.373} \times 0.2-0.166 \times 0.2\right]$ for a highwage firm at the $90 \%$ wage quantile $\left(w_{s} / w^{\min }=4.683\right)$. Hence, any minimum wage increase translates approximately one-to-one into an average firm wage increase for the low-wage firm.

The estimated (non-linear) relationship between a minimum wage increase and the average wage increase is similar for all three firm size groups. This is illustrated in Figure 3, which plots 
the convex impact function for small, medium, and large firms together with a histogram of the firm distribution of the firm wage relative to the minimum wage. For small and medium firms, the average wage increase is roughly $22 \%\left[\Delta \ln \left(w^{\min }\right)=0.2\right]$ for firms with an average wage close to the minimum wage $\left(w_{s} / w^{\text {min }}=1\right)$, which suggests that the non-linear impact function is correctly estimated at the low end of the wage distribution. For the large firm sample we find point estimate for the average (log) wage effect somewhat larger than $20 \%$ close to the limit case with $w_{s} / w^{\text {min }}=1$, but the (bootstrapped) standard error are also higher for large firms.

Overall, we find that minimum wage changes have a highly heterogeneous effect on the average labor cost of Chinese manufacturing firms and this heterogeneous exposure can be proxied by the convex function $I F_{s}=\left(w_{s} / w^{\text {min }}\right)^{-(k+1)}$, where the relative "closeness" of the minimum wage $w^{\text {min }}$ to the average firm wage $w_{s}$ determines the (non-linear) firm exposure to any further minimum wage increases. The effective firm exposure is given by the interaction term $I F_{s} \times \Delta \ln w^{\min }$ and can be used in reduced form regressions to capture the firm response to the labor cost shock.

While the interaction term $I F_{s} \times \Delta \ln w^{\text {min }}$ allows for a more precise identification of the labor cost shock across firms with different average wages, it is (by construction) related to certain firm characteristics and cannot be considered a pure random assignment. To document this aspect, we split the three firm panels for SOEs, private-owned and foreign-owned firm into firm years with an above median (Sample 1) and below median (Sample 2) interaction term $I F_{s} \times \Delta \ln w^{\min }$. In Table 3, we report summary statistics for sample differences in various firm characteristics, such as $(\log )$ sales value $[\ln ($ Sales $)]$, (log) labor input, (log) capital $[\ln (K)]$, the $(\log )$ capital to labor ratio $[\ln (K / N)]$, firm profit margin as the ratio of net income to to sales, $(\log )$ assets $[\ln ($ assets $)]$, and two measures of total factor productivity $[\ln (A 1)$ and $\ln (A 2)]$. Column (3) of Table 3 reports the (percentage) difference between the two samples and Columns (4) and (5) report test statistics for null hypothesis of equal sample means and equality of the sample distribution, respectively. The null hypothesis that firm characteristics are identical across both samples can be rejected at high levels of statistical confidence. This is not surprising, given that Sample 1 contains a much larger share of low-wage firms (with high IF values). The largest sample difference concerns the average (log) firm sales, where the most exposed firms in Sample 1 have (log) sales that are on average $-62.1 \%,-18.1 \%$, and $-36.2 \%$ lower than less exposed SOEs, private-owned and foreign-owned firms, respectively. Similarly, 
the most exposed firms feature an average (log) capital to labor ratio $(K / N)$ that is $-32.9 \%$, $-14.2 \%$, and $-57.4 \%$ lower for SOEs, private-owned and foreign-owned firms. Also, profit margins tend to be lower for the most exposed firms with log differences of $-2.8 \%,-0.7 \%$, and $-1.2 \%$, respectively.

In order to account for these differences between exposed and non-exposed firms and reduce the role of omitted variables, we include firm fixed effects in all reduced form specifications with a dependent variable defined in log growth rates. ${ }^{10}$ Hence, we allow for the firm-specific growth trends of any dependent variable and identification comes entirely from a firm's time-varying exposure to minimum wage changes and particular of those low-wage firms with a high exposure term $I F$.

\section{Evidence}

\subsection{Labor Substitution under Minimum Wage Shocks}

Proposition 1 predicts that an adverse minimum wage shock should provoke a relative input substitution for the most exposed low-wage firms. This labor substitution should occur independently of change in firm productivity in response to the adverse labor cost shock. Our identification relies on the interaction variable $I F_{s} \times \Delta \ln w^{\min }$, which captures the heterogeneous firm exposure under minimum wage shocks $\Delta \ln w^{\text {min }}$. Any general correlation between minimum wage changes and changes in the capital to labor ratio of all firms is captured by the covariate $\Delta \ln w^{\min }$, and any cross-sectional growth differences for the capital to labor ratio related to low wage employment by the level covariate $I F_{s}$ and by firm fixed effects. Our baseline regression specification also allows for serial correlation of the capital to labor ratio in a dynamic panel specification

$\Delta \ln (K / N)_{s, t}=\alpha \Delta \ln (K / N)_{s, t-1}+\beta\left[I F_{s} \times \Delta \ln w^{\min }\right]+\gamma I F_{s}+\delta \Delta w^{\min }+\mu_{\text {Ind } \times \text { Year }}+\nu_{s}+\epsilon_{s, t}$,

where $\mu_{\text {Ind } \times \text { Year }}$ represents interacted industry and time fixed effects and $\nu_{s}$ the firm fixed effects. The average trend rate of capital to labor substitution can therefore be firm specific.

\footnotetext{
${ }^{10}$ The DGMM estimator then uses again time differencing to eliminate the firm fixed effects and obtains consistent dynamic panel estimates.
} 
Table 4 reports the regressions for the labor to capital substitution effect. The reported standard errors are clustered at the country-year level. The first column represents the least square dummy variable regression (LSDV) that controls for firm-specific trends in the capital to labor ratio based on a large set of dummy variables. Given the short time span of our panel, this specification implies a downward estimation bias for the lagged dependent coefficient $\alpha$. To avoid this dynamic panel bias, in all consecutive columns we report the difference general method of moments (DGMM) estimates that deliver consistent estimates of the lagged dependent variable coefficient. Only the lagged dependent variable is instrumented with its own lagged value (at lag 2), while all other right-hand side variables are included directly in the instrument set and are thus treated as exogenous.

The point estimate in Column (2) for the lagged dependent variable is less negative under DGMM compared to the LSDV coefficients in Columns (1), which conforms to the predicted bias. The interaction term $I F_{s} \times \Delta w^{\text {min }}$ as the main coefficient of interest is positive with a statistically highly significant point estimate of 0.343 . The additional inclusion of interacted industry and time fixed effects in Column (3) reduces this point estimate only slightly. Consider a $20 \%$ increase in the minimum wage for a low- and high-wage firm at that $10 \%$ and $90 \%$ quantile of the distribution for $w_{s} / w^{\text {min }}$ with values for the impact factor of 0.629 and 0.119 , respectively. The firm difference in the labor to capital substitution follows as $10.2 \%[=(0.629-0.119) \times$ 0.2 , which corresponds to more than one year of the average annual substitution effect of 9.1\%. Hence, a minimum wage increase by $20 \%$ accelerates the labor to capital substitution by approximately one year (of trend substitution) for the most affected firms.

The standard errors reported in parenthesis are clustered at the country-year unit, which corresponds to the treatment effect. However, the convexity parameters $k$ in the impact function $I F_{s}$ are estimated which renders the standard errors in the main regression inaccurate. To correct for the estimated regressor problem, we also report (block) bootstrapped standard errors in brackets which are obtained by 500 sample draws with the county as the block unit and reestimation of the parameters $k$ for each sample draw. However, the bootstrapped standard errors tend to be only slightly large and do not substantially affect the high level of statistical significance for the variable of interest.

To explore sample heterogeneity with respect to firm size and TFP level, we define additional dummies $\left(D_{-} x\right)$ marking small, medium, and large firms as well as firms with low (below 
median) and high (above median) TFP, respectively. Using triple interactions in Columns (4) and (5) with the respective subsample dummies, we can decompose the coefficient $\beta$ according to the contribution of each subsample. The point estimates suggest that the labor to capital substitution is stronger for private-owned firms than for SOEs and takes on the largest point estimate of 0.684 for foreign owned firms. This suggests that foreign-owned firms react more vigorously to the labor cost shock. By contrast, we find a similar labor to capital substitution effect for firms sorted within any industry based on a low or high (initial) TFP level. Columns (6) and (7) repeat the regression for the subsamples of SOEs and foreign owned firms. The estimated substitution effects in the subsamples are almost identical to the respective point estimates in the pooled regression in Column (4).

\subsection{Production Response to Minimum Wage Increases}

Next, we explore the minimum wage effect for (value added) firm output, labor input, capital employed and the profit margin. Unlike for the change in the capital to labor ratio, the predicted effects are ambiguous for output and input measures and depend on the endogenous response of total factor productivity to the averse labor cost shock. In the absence of any differential change in total factor productivity for low-wage firms, firm output and inputs for employment and capital should all decrease because a low-wage firm faces an increased competitive disadvantage following a minimum wage increase. However, a strong endogenous increase in total factor productivity can overturn these predictions: If total factor productivity increases more for lowwage firms under the new adverse labor market conditions, output of the low-wage firm can remain constant or even increase even though labor input decreases.

In Table 5 we present the dynamic panel regressions, where the specifications follow the previous setup in Table 4, Columns (4) and (5) with interaction dummies $D \_x$. Formally,

$$
\begin{aligned}
\Delta \ln Z_{s, t}= & \alpha \Delta \ln Z_{s, t-1}+\sum_{x} \beta_{x}\left[I F_{s} \times \Delta \ln w^{\min } \times D_{-} x\right]+\sum_{x} \delta_{x}\left[\Delta \ln w^{\min } \times D_{-} x\right]+ \\
& +\sum_{x} \gamma_{x}\left[I F_{s} \times D_{-} x\right]+\sum_{x} \theta_{x} D_{-} x+\mu_{\text {Ind } \times Y e a r}+\nu_{s}+\epsilon_{s, t},
\end{aligned}
$$

where $Z_{s, t}=Y_{s, t}, N_{s, t}, K_{s, t}, P M_{s, t}$ denote (value added) firm output, labor input (employment), capital and profit margin, respectively. The dummies $D_{-} x$ mark alternatively SOEs $\left(D_{-} S O E\right)$, 
private-owned firms ( $D \_$private) and foreign-owned firms (D_foreign) in Columns (2), (5), (8) and (11); or low- and high-TFP firms (based on initial levels marked D_low TFP and D_high TFP, respectively) in Columns (3), (6), (9) and (12). We report in parenthesis robust standard errors for the one-step estimator clustered at the county/city-year unit and (block) bootstrapped standard errors in brackets accounting for the error in the estimated covariate $I F_{s}$.

In Table 5, Column (2), foreign-owned firms show a statistically significant positive coefficient $\beta$, while SOEs do not feature any accelerated output growth when exposed to a large minimum wage shock with $I F_{s} \times \Delta \ln w^{\min } \gg 0$. For private-owned exposed firms, the output increase is also positive, but not statistically significant at the conventional $1 \%$ level. None of the three firm types shows any average decrease in the value added output for the most adversely affected firms as economic theory predicts in the absence of relative productivity increases in low-wage firms. Column (3) reveals that the output growth acceleration is more pronounced among firms with (initially) below median TFP.

Columns (4), (5) and (6) provide the corresponding dynamic panel results for employment growth as the dependent variable. The small negative coefficient of -0.056 for the lagged dependent variable suggests that employment growth changes are very persistent. The coefficients of interest for the interaction terms $I F_{s} \times \Delta \ln w^{\min } \times D_{-} x$ are uniformly negative and statistically significant for all three firm type groups with foreign-owned firms showing the largest relative employment growth reduction. A $20 \%$ increase in the minimum wage reduces relative employment growth for foreign-owned low-wage firms (at the $10 \%$ quantile where $w_{s} / w^{\min }=1.557$ ) by $-4.4 \%\left[=-0.406 \times(1.557)^{-1.361} \times 0.2\right]$ compared to $-0.7 \%\left[=-0.406 \times(5.716)^{-1.361} \times 0.2\right]$ for high-wage firms (at the $90 \%$ quantile where $w_{s} / w^{\min }=5.716$ ) in the same industry sector. Column (6) reveals that the relative employment growth reduction is larger for firms with below median (initial) TFP than for those with above median TFP.

Columns (7)-(9) of Table 5 document the minimum wage effect on changes in the capital stock dynamics. Unlike SOEs, private-owned and foreign-owned firms at the low end of the wage spectrum show a statistically significant relative growth in their capital stock in the year of the minimum wage hike. The increased capital spending is concentrated in firms which already have an initial TFP level above the median. Columns (10)-(12) report the corresponding findings for the profit margin, which increases most for the privately owned firms and for firms with 
high initial TFP.

Overall, the endogenous firm response to the minimum wage increase is at odds with the predicted relative decrease in output growth under constant firm productivity growth. Particularly private-owned and even more so for foreign-owned firm feature accelerated output growth which point to the productivity leap in the year of the minimum wage increase. The next section examines this issue in more detail.

\subsection{Total Factor Productivity and Minimum Wage Shocks}

For the production function in value added output $Y$, we define the change in total factor productivity $\Delta \ln A_{s, t}$ as the change in the log difference between value added output and the value of labor input and capital using the factor shares $\alpha_{L}$ and $\alpha_{K}$,

$$
\begin{aligned}
\Delta \ln A_{s, t} & =\ln A_{s, t}-\ln A_{s, t-1}= \\
& =\ln Y_{s, t}-\ln Y_{s, t-1}-\alpha_{L}\left(\ln w_{s, t-1} N_{s, t}-\ln w_{s, t-1} N_{s, t-1}\right)-\alpha_{K}\left(\ln K_{s, t}-\ln K_{s, t-1}\right) .
\end{aligned}
$$

To discard any direct price effect of the minimum wage increase on the TFP measurement, we use lagged average wages $w_{t-1}$ to evaluate the total labor costs $w_{t-1} N_{t}$ in period $t$.

Measurement of the parameters $\alpha_{L}$ and $\alpha_{K}$ of the production function is sensitive to reporting and measurement errors in firm input and output. ${ }^{11}$ Therefore, we opt for the most robust method of cost shares based inference to estimate $\alpha_{L}$ and $\alpha_{K}$. In the absence of adjustment costs, cost minimization implies that the factor shares should be proportional to the cost share of labor and capital, hence the labor and capital shares follow as

$$
\alpha_{L}=\alpha_{L}(s, t)=\frac{w_{s, t-1} N_{s, t}}{w_{s, t-1} N_{t}+r K_{s, t}} \quad \text { and } \quad \alpha_{K}=\alpha_{K}(s, t)=\frac{r K_{s . t}}{w_{s . t-1} N_{s, t}+r K_{s, t}}
$$

respectively. For the cost of capital we assume a constant rate $r=7 \%$ for all firms. ${ }^{12}$

Our baseline results use TFP growth $\Delta \ln A 1_{s, t}$ based on the time series average of $\alpha_{L / K}(s, t)$ for all observations available for the same firm. In the following section we consider alternative

\footnotetext{
${ }^{11}$ The Chinese firm data are based on firm surveys and collected independently of the internal accounting procedures of the firms. We also note that career concerns may provoke deliberate misreporting if the survey data are suspected of being used for ulterior performance evaluations and comparisons.

${ }^{12}$ Using $5 \%$ or $9 \%$ instead did not qualitatively change any of the results.
} 
measures for the calculation of the factor shares and show that the results are robust. Inferring the factor shares from cost shares has the advantage that the inference is relatively robust to measurement errors. Output $\ln Y_{s, t}$ does not even enter the calculation, so any respective mismeasurement is irrelevant. Moreover, any regression-based inference about factor shares is based on minimizing squared mean deviations so that misreported outliers can severely distort the inference, while simple averaging over values of $\alpha_{L / K}(s, t)$ represents a more robust linear operation.

As before, we use a dynamic panel specification for TFP growth $\Delta \ln A 1_{s, t}$ with the interaction term $I F_{s} \times \Delta \ln w^{\text {min }}$ as the main regressor of interest. The corresponding level effect for the firm-specific impact function $I F_{s}$ and the city-level minimum wage change $\Delta \ln w^{\min }$ are included as control variables in the specification

$\Delta \ln A 1_{s, t}=\alpha \Delta \ln A 1_{s, t-1}+\beta\left[I F_{s} \times \Delta \ln w^{\min }\right]+\gamma I F_{s}+\delta \Delta \ln w^{\min }+\mu_{\text {Ind } \times Y e a r}+\nu_{s}+\epsilon_{s, t}$,

where $\mu_{\text {Ind } \times \text { Year }}$ denotes the interacted industry and year fixed effects, and $\nu_{s}$ represents the firm fixed effects.

Table 6, Column (1), reports the Least Square Dummy Variable (LSDV) regression with time and firm fixed effects, Column (2) the corresponding DGMM regression, while Column (3) and all other regressions add the interacted industry and year fixed effects. Similar to Table 4 , we use dummy variable $\left(D_{-} x\right)$ for SOEs, private-owned and foreign-owned firms in Column (4) and low and high (initial) TFP in Column (5) to mark firm subsamples and identify the subsample-specific coefficient $\beta_{x}$.

The positive productivity effect for low-wage firms is statistically significant for all three specifications in Columns (1) to (3) with point estimates for $\widehat{\beta}$ of approximately 0.24 for the overall firm sample. This provides evidence for an average endogenous productivity response to minimum wage shocks. More interesting still are the results which decompose this average effect by firm type in Columns (4) to (7). We find a particularly strong endogenous productivity response for foreign-owned firms with a coefficient $\widehat{\beta}_{\text {foreign }}=0.669$ and low-TFP firms with $\widehat{\beta}_{\text {low TFP }}=0.921$, in Columns (4) and (5), respectively. The point estimate of $\widehat{\beta}=0.669$ implies that a minimum wage increase of $20 \%$ increases productivity of a low-wage firm (at the $10 \%$ quantile where $\left.w_{s} / w^{\text {min }}=1.557\right)$ by $7.3 \%\left[=0.669 \times(1.557)^{-1.361} \times 0.2\right]$ compared 
to $1.2 \%\left[=0.669 \times(5,716)^{-1.361} \times 0.2\right]$ for a high-wage firms (at the $90 \%$ quantile where $\left.w_{s} / w^{\min }=5.716\right)$ in the same industry sector. By comparison, the average annual TFP growth among foreign-owned firms is $10.3 \%$. The additional TFP growth of $7.3 \%$ for low-wage firms therefore accounts for a growth acceleration equivalent to approximately nine month of trend growth. As a robustness check, we also undertake subsample regression for SOEs in Column (6) and foreign-owned firms in Column (7). We note that the point estimates obtained for the subsamples are very similar to the corresponding coefficients in Column (4) at $\widehat{\beta}_{S O E}=0.139$ for SOEs [Column (6)] and $\widehat{\beta}_{\text {foreign }}=0.601$ for foreign-owned firms [Column (7)].

Overall, we find that minimum wage hikes accelerate TFP growth (relative to industry peers) in the exposed private-owned firms and even more so in the exposed foreign-owned firms, but not in SOEs. These productivity gains are consistent with the constant or increased value added output under lower labor inputs reported in Table 5. We also find that the initial firm TFP matters for the strength of the endogenous productivity response. The following section sorts firms into those with high and low initial TFP and shows that ownership matters for both subsamples when explaining the endogenous productivity response.

\subsection{Initial Firm TFP and the Ownership Effect}

A low initial firm TFP implies that a firm has more scope to increase productivity as it is further from the industries' efficient frontier. To isolate this "productivity catch-up effect" from the "ownership effect', we sort in Table 7 firms by their initial TFP into a high- and low-TFP subsample and repeat the regression in Table 6, Column (4). We only reports the coefficient for the lagged dependent variable and the triple interaction terms. Panel A uses the productivity measures $A 1$ introduced in Section 5.3 and Panel B an alternative TFP measure $A 2$, discussed in Section 6.1. Columns (1) and (2) report the regression results for the full sample of all firms, while Columns (3) and (4) focus on the sample of low-TFP firms and Columns (5) and (6) on high-TFP firms.

Column (1) shows again that the positive TFP effect of minimum wage increases is concentrated in private-owned firms and those with foreign ownership. State-owned enterprises do not feature a statistically significant TFP acceleration in the year of the minimum wage shock. This result is robust to the inclusion of interacted industry and year fixed effects in Column 
(2), which replicates Column (4) of Table 6.

A comparison with the regression results for the subsamples of low- and high-TFP firms in Columns (3)-(4) and (5)-(6), respectively, shows that firms with a low initial TFP experience a much larger TFP acceleration. But again, SOEs do not show any productivity improvement even if their initial TFP is low. Figure 4 provides a graphical illustration of the quantitative importance of minimum wage increases for the acceleration of firm productivity growth. The graph shows the large difference in the estimated productivity growth between a low-wage and a high-wage firm implied by a $22 \%$ minimum wage increase $\left[\Delta \ln \left(w^{\min }\right)=0.2\right]$ for firms of different ownership types and initial TFP level (below versus above median). Low productivity firms under foreign ownership show by far the largest relative TFP gain.

We conclude that the relative productivity acceleration in low-wage firms in the year of the minimum wage increase is strongly contingent on firm ownership. This finding favors a narrative of X-efficiency, according to which only private-owned and foreign-owned firms meet the challenge of the labor cost shock and restructure accordingly. Such restructuring also implies more capital expenditure, as shown in Table 5, Column (8), where we identify the role of ownership in the adjustment of the capital stock. Private-owned and particularly foreignowned firms increase their capital expenditure under an adverse labor cost shock, but no such reaction is seen for SOEs. We note that capital constrains cannot account for these differences as Chinese SOEs generally face fewer financial constrains than private-owned firm. Similarly, the employment growth reduction is considerably greater in private-owned and foreign-owned firms compared to SOEs as shown in Table 5, Column (5).

\subsection{Productivity Effect by Management Practice}

The particularly strong TFP response of foreign firms to adverse labor cost shocks could be explained by better management practices in these firms. While (foreign) ownership is the ultimate cause, differences in management practices could represent a proximate cause for the observed heterogeneous firm response to labor cost shocks. To explore this channel, we draw on survey data about management practices in 564 Chinese firms sampled in 2006, 2007, 2008, and 2010 by Bloom and van Reenen (2010). The data are based on telephone interviews that evaluate the quality of firm management in three dimensions: (1) monitoring practices (the 
collection and processing of production information); (2) target-setting practices (the ability to set coherent, binding short- and long-term targets); and (3) incentive practices (merit-based pay, promotion, hiring, and firing). ${ }^{13}$ Responses along these three dimensions of management quality are then aggregated to a firm-specific management score.

We are able to match 548 survey observations to our firm data and find that foreign firms indeed feature a higher average management score that is $9 \%$ above the corresponding average for private Chinese-owned firms. Private Chinese-owned firms also show a slightly higher average management score than SOEs after controlling for firms size. To extrapolate these survey observations to the full firm sample, we use a simple linear regression model that explains the survey observations as a linear function of three ownership types (SOE, private, foreign) and firm size (log asset). Assuming the representativeness of the survey sample, we then predict the management scores (Mgmt_Score) of all other firms based on ownership type and firm size.

Table 8 replaces the ownership dummies in Table 6 by the (predicted) management score to explore whether this can equally account for the heterogeneous firm response to adverse labor shocks. The interaction coefficient of interest $I F_{s} \times \Delta \ln d w^{\min } \times M g m t$ Score is significant

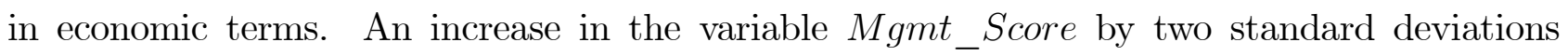
$(=0.95)$ multiplied by the $90 \%$ quantile value of $I F_{s} \times \Delta \ln d w^{\min }(=0.082)$ implies for the point estimate 0.989 in Column (4) a TFP acceleration of $7.7 \%$ in the year of the minimum wage increase relative to a trend growth of $12.3 \%$ a year.

Measurement errors related to the survey data and prediction errors in the extrapolation to

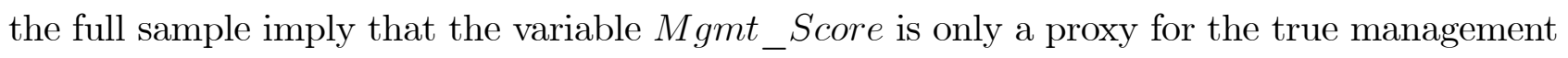
quality of Chinese firms. Both errors should attenuate the size of the point estimate. To adjust the corresponding standard error for the estimated regressor problem, we jointly bootstrap the predictive regression based on the survey sample and block bootstrap the DGMM regression to obtain valid standard errors reported in brackets. For low-TFP firm in Columns (3) and (4), we still obtain statistical significance for the coefficient of interest at the 5 percent significance level.

Overall, the evidence supports the interpretation that management quality represents an important determinant for a successful endogenous firm response to minimum wage shocks. Good management practices appear to be particularly valuable if the competitive pressure

\footnotetext{
${ }^{13}$ Compare Bloom et al. (2010) and Bloom and van Reenen (2007, 2010).
} 
increases; implying that they are in a complementary relationship to competitive forces.

\section{Robustness}

This section explores the stability of the results in three dimensions. First, we verify that alternative inference about the productivity parameters $\alpha_{L}$ and $\alpha_{K}$ of the production function confirm the results described in the previous section. A second robustness check concerns the issue of firm exit and entry, where we reproduce the results with a balanced panel of firm reporting in every sample year. Third, we use an independent data source from the Chinese custom authorities to show that the relative productivity surge in private-owned and foreignowned firms after minimum wage hikes is also reflected in higher export volumes, which makes output and output price mismeasurement a less plausible explanation for the findings.

\subsection{Alternative Productivity Measures}

In Section 6.3, we calculate TFP growth using productivity parameters $\alpha_{L}$ and $\alpha_{K}$ derived from a firm's average factor cost share of labor and capital, respectively. While this inference does not impose any common productivity structure across firms in the same industry, it ignores any intertemporal change in the factor shares. An alternative approach is to assume common productivity parameters within an industry, but variability across time: Our second measure of TFP growth $\Delta \ln A 2_{s, t}$ is therefore based on the intra-industry average of $\alpha_{L / K}(s, t)$ for all firm observations within a given industry and year.

Table 7, Panel B, repeats the regressions in Panel A for this alternative measure of TFP growth. The regression results for the coefficient $\beta$ in the DGMM regressions are very similar to those in Table 7, Panel A. For example, the point estimate for the interaction term $I F_{s} \times$ $\Delta \ln w^{\min } \times D \_$foreign in Columns (4) and (6) of Panel A are 1.023 and 0.368 for low- and highTFP firms, respectively, compared to 0.981 and 0.371 in Panel B, respectively. This suggests that our inference about TFP growth is not sensitive to the assumed time invariance of the firm parameters $\alpha_{L}$ and $\alpha_{K}$.

A third and more general inference about the productivity parameters $\alpha_{L}$ and $\alpha_{K}$ consists in a panel regression of the firm-year observations $\alpha_{L / K}(s, t)$ on both firm and interacted industry and time fixed effects. The predicted value $\widehat{\alpha}_{L / K}(s, t)$ then represents a combination of time 
and cross-sectional intra-industry averaging of cost shares. The corresponding third measure of TFP growth $\Delta \ln A 3_{s, t}$ again yields quantitatively similar results that associate adverse labor cost shocks with higher TFP growth.

Firm output may also be influenced by latent variables like capacity utilization and overtime work, which do not enter the input measurement. Levinsohn and Petrin (2003) propose the use of other intermediate inputs in order to estimate such unobservable output contributions. This can improve the estimation of productivity parameters if inputs and outputs are not subject to measurement error. Chinese manufacturing data do not lend themselves to these methods and require more robust inference methods.

Time-varying unobservable input variations cannot be excluded as a contribution to the measured output increases and may overestimate the productivity gain under minimum wage shocks. However, if we are willing to assume that such unobservable input factors play a similar role for SOEs and private firms, the conclusion about the relatively stronger productivity increase in the private sector should be robust.

\subsection{Sample Selection Issues}

The unbalanced nature of our firm sample suggests that low-productivity firms could drop out of the sample and that any evidence for positive TFP growth related to minimum wage shocks could simply represent a selection effect of surviving firms. However, a comparison of the groups of most and least exposed firms in Table 3 shows that their difference in profitability is economically very modest at around only $1 \%$ for all three firm size groups. Selection bias due to profitability differences between low- and high-wage firms is therefore not very likely.

To further exclude that sample entry or exit accounts for the TFP growth effect, we reproduce the results in Table 7 for a balanced panel of firms that report in every year. The results are shown in Table 9 for the productivity measure $A 1$. The number of firm-year observations drops from more than 200,000 in the unbalanced panel to less than 70,000 in the balanced panel. Nevertheless we find a qualitatively similar pattern with statistically significant interaction coefficients in the low-TFP sample, but not in the high-TFP sample. If anything, the point estimates for the TFP catch-up effect under adverse cost shocks are even larger than before. We exclude that the positive TFP effect is induced by selection issues related to an unbalanced 
panel. ${ }^{14}$

\subsection{Output Mismeasurement}

The output and TFP measures used so far are imputed using the industry price deflator. This is likely to generate a measurement bias if the pass-through of factor price changes - including the minimum wage increase itself - is firm-specific and not correctly captured by the industry price deflator. Thus, the output or TFP growth could be overestimated precisely in cases where firms face a large labor cost increase. To discard such an output mismeasurement hypothesis, we draw on Chinese custom data that allow a decomposition of the export value into a volume and a price component at the firm level.

Table 10 reports panel regressions with changes in (log) export value $(\Delta \ln$ Exp_Value), changes in (log) export volume $\left(\Delta \ln E x p \_\right.$Volume), and a change in the log unit prices $(\Delta \ln$ Exp_Price) as the dependent variable for 89,068 firm-year observations. The DGMM regressions use firm and year fixed effects in Columns (1), (3), and (5) and additional interacted industry and year fixed effects in Columns (2), (4), and (6). In line with the productivity surge in low-wage firms under private or foreign ownership, we find that the value of exports under a wage shock increases for private-owned and foreign owned firm, but not for state-owned enterprises. This parallel finding for export values is reassuring because the data here are independently collected by the Chinese custom authorities. A value decomposition into a volume and price component in Columns (3)-(4) and (5)-(6) reveals that the export value increase in private-owned and foreign-owned firms can be attributed to higher export volumes and not to increased output prices. Exporting firms do not pass through the minimum wage increase to higher unit export prices, but rather increase export volume, which is consistent with a simultaneous increase in firm productivity. ${ }^{15}$

\footnotetext{
${ }^{14}$ In a related paper, Mayneris, Poncet, and Zhang (2015) suggest that minimum wage increases in China trigger exit by less productive firms. We run additional probit regression for firm survival in 2008 based on the Chinese Economic Census, but do not find robust evidence that minimum wage shocks increase the probability of market exit.

${ }^{15}$ In related work, Gan, Hermandez and Ma (2015) find that minimum wage hikes decrease profitability of Chinese exports, but their work does not focus on the productivity response by firm ownership type.
} 


\section{Conclusion}

This paper explores the endogenous productivity response to adverse competitive shocks based on Chinese firm data from the manufacturing sector. The frequency and large cross-sectional variation of minimum wage shocks in China provide a unique opportunity to identify a policy shocks exogenous to a firm's technological progress.

In line with neoclassical firm theory, we find that low-wage firms show a larger labor to capital substitution in the year of a minimum wage increase compared to high-wage industry peers. However, their relative real output growth (and market share) is not diminished, because the relative labor cost increase due to higher minimum wages is compensated by higher firm productivity. We also look for heterogeneity in the relative productivity gains of low-wage firms and find that it is highly contingent on both ownership type and initial productivity level. Private-owned firms, particularly foreign-owned firms, account for much of the productivity acceleration effect of minimum wage increases, whereas state-owned firms show no evidence for a (relative) productivity leap in the year of the minimum wage increase. Based on survey evidence on management practices in China (Bloom and van Reenen, 2010), we argue that the high reactiveness of foreign firms is well explained by their considerably higher management scores.

Our research focus on Chinese manufacturing firms for the period 2002-08 may raise questions about the external validity of the nexus between labor cost changes and firm productivity growth. The declining productivity growth in the developed world over the last two decades certainly coincides with very low (or even negative) real wage growth of low income workers. Could the low real wage growth in developed countries and/or access to cheap labor in emerging economies have slowed the adoption of new labor-saving technologies - thus contributing to the observed productivity slowdown? Irrespective of the correct answer, the Chinese data also provide a warning that a deliberate minimum wage policy may not necessarily deliver productivity gains if inflated wages fall into an unresponsive public sector with little intrinsic capacity to adjust and innovate. More research is needed on exactly what makes organizations and firms responsive to competitive challenges and drives innovation. 


\section{References}

[1] Aghion. P., M. Dewatripont, and P. Rey, 1999, Competition, Financial Discipline and Growth, Review of Economic Studies, 66, 825-852.

[2] Autor, D. , D. Dorn, G.H. Hanson, G. Pisano, and P. Shu, 2016, Foreign Competition and Domestic Innovation: Evidence from U.S. Patents, unpublished working paper.

[3] Bena, J, and E. Simintzi, 2016, Labor-induced Technological Change: Evidence from Doing Business in China, Unpublished working paper.

[4] Bernard, A. B., Jensen, J. B. and Schott, P. K., 2006, Transfer pricing by US-based multinational firms, NBER working paper (No. w12493), National Bureau of Economic Research.

[5] Bloom, N., M. Draca, and J. van Reenen, 2015, Trade Induced Technical Change? The Impact of Chinese Imports on Innovation, IT and Productivity , Review of Economic Studies, forthcoming.

[6] Bloom, N., A. Mahajan, D. McKenzie, and J. Roberts, 2010, Why do firms in developing countries have low productivity? American Economic Review, 100(2), 619-23.

[7] Bloom, N., and J. van Reenen, 2007, Measuring and Explaining Management Practices across Firms and Countries, Quarterly Journal of Economics, 122(4), 1351-408.

[8] Bloom, N. and J. van Reenen, 2010, Why do Management Practices Differ across Firms and Countries?, Journal of Economic Perspective, 24(1), 203-24.

[9] Boltho, A., 1998, Convergence, Competitiveness and the Exchange Rate. In: Post War European Economic Growth, edited by N. Crafts and G. Toniolo, 107-30.

[10] Bowen III, D. E., L. Frésard, and J. Taillard, 2015, What's your Identification Strategy? Innovation in Corporate Finance Research, Robert H. Smith School unpublished research paper. 
[11] Brown, C., 1999. Minimum Wages, Employment, and the Distribution of Income. In: Ashenfelter, O., and Card, D. (Eds.), Handbook of Labor Economics, Elsevier, vol. 3, 2101-2163.

[12] Card, D., and A. Krueger, 1994, Minimum Wages and Employment: A Case Study of the Fast-Food Industry in New Jersey and Pennsylvania, American Economic Review 84(4), 772-793.

[13] Casale, G., C.-Y. Zhu, 2013, Labour Administration Reforms in China, International Labour Office, Geneva.

[14] Dube, A., W. Lester, and M. Reich, 2015, Minimum Wage Shocks, Employment Flows and Labor Market Frictions, Journal of Labor Economics, forthcoming.

[15] The Economist, 2016, Free exchange, Doing less with more, Edition 3/20/2016, 69.

[16] Efing, M., R. Fahlenbrach, C. Herpfer, and P. Krüger, 2016, How do Investors and Firms React to an Unexpected Currency Appreciation Shock? SFI working paper, 2016.

[17] Fang, T., and C. Lin, 2013, Minimum Wages and Employment in China, IZA, Discussion Paper No.7813.

[18] Foster, L., J. Haltiwanger, C. Krizan, 2001, Aggregate Productivity Growth. Lessons from Microeconomic Evidence. In: Hulten, C., Dean, D., and Harper, M. (Eds.), New Developments in Productivity Analysis, University of Chicago Press, 303-372.

[19] Frésard, L., and P. Valta, 2016, How Does Corporate Investment Respond to Increased Entry Threat? Unpublished working paper.

[20] Gan, L., M. A. Hermandez, and S. Ma, 2015, The Higher Costs of Doing Business in China: Minimum Wages and Firms' Export Behavior, Journal of International Economics 100, 81-94.

[21] Haepp, T., and C. Lin, 2015, How Does the Minimum Wage Affect Firm Investment in Fixed and Human Capital? Evidence from China, working paper at http://www.solejole.org/Haepp-Lin.pdf. 
[22] Hsieh, C-T. , and P. Klenow, 2009, Misallocation and Manufacturing TFP in China and India, Quarterly Journal of Economics 124, 1403-1448.

[23] Hsieh, C-T., and P. Klenow, 2014, The Life Cycle of Plants in India and Mexico, Quarterly Journal of Economics 129, 1035-1084.

[24] Hsieh, C-T., and R. Ossa, 2011, A Global View of Productivity Growth in China, Unpublished working paper, University of Chicago, Chicago.

[25] Hsieh, C-T., and Z. Song, 2015, Grasp the Large, Let Go of the Small, Brookings Papers in Economic Activity, forthcoming.

[26] Huang, Y., P. Loungani, and G-W. Wang, 2014, Minimum Wages and Employment Dynamics: Evidence from China, IMF working paper, WP/14/148.

[27] Jia, Peng, 2014, Employment and Working Hour Effects of Minimum Wage Increase: Evidence from China, China \& World Economy 22(2), 61-80.

[28] Katz, L., and A. Krueger, 1992, The Effect of the Minimum Wage on the Fast-Food Industry, Industrial and Labor Relations Review, 46(1), 6-21.

[29] Leibenstein, H.,1966, Allocative Efficiency vs. "X-Efficiency", American Economic Review $56(3), 392-415$.

[30] Levinshohn, J., and A. Petrin, 2003, Estimating Production Functions Using Inputs to Control for Unobservables, Review of Economic Studies 70(2), 317-342.

[31] Lileeva, A., and D. Trefler, 2010, Improved Access to Foreign Markets Raises Plant-level Productivity... For Some Plants, Quarterly Journal of Economics,125 (3). 1051-1099.

[32] Long, C., and J. Yang, 2016, How Do Firms Respond to Minimum Wage Regulation in China? Evidence from Chinese Private Firms, China Economic Review 38, 267-284.

[33] Mayneris, F., S. Poncet, and T. Zhang, 2015, The Cleansing Effect of Minimum Wages, unpublished working paper.

[34] Meer, J., and J. West, 2013, Effects of the Minimum Wage on Employment Dynamics, Unpublished working paper, National Bureau of Economic Research. 
[35] Neumark, D., I. Salas, and W. Wascher, 2014, Revisiting the Minimum Wage: Employment Debate: Throwing Out the Baby with the Bathwater? Industrial and Labor Relations Review 67(2.5), 608-648.

[36] Neumark, D., and W. Wascher, 2008, Minimum Wages, MIT Press, Massachusetts.

[37] Pessoa, J.P., and J. Van Reenen, 2013, The UK Productivity and Jobs Puzzle: Does the Answer Lie in Labour Market Flexibility?, Centre for Economic Performance, special working paper.

[38] Porter, M.E., 1990, The Competitive Advantage of Nations. New York: Free Press.

[39] Schmidt, K., 1997, Managerial Incentives and Product Market Competition, Review of Economic Studies, 64, 191-213.

[40] Song, Z., K. Storesletten, and F. Zilibotti, 2011, Growing like China, American Economic Review 101(1), 196-233.

[41] Song, Z., and G.-Y. Wu, 2015, Identifying Capital Misallocation, unpublished working paper, University of Chicago, Chicago.

[42] Su, H., and X. Wang, 2014, Evolution of the Minimum Wage System in China and Its Effects, unpublished working paper, Research Department, Ministry of Human Resources and Social Security of China.

[43] Syverson, C., 2011, What Determines Productivity? Journal of Economic Literature 49(2), 326-65.

[44] Wang, J., and M. Gunderson, 2012, Minimum Wage Effects on Employment and Wages: Diff-in-Diff Estimates from Eastern China, International Journal of Manpower, 33(8), 860876.

[45] Zhu, X-D., L. Brandt, and T. Tombe, 2013, Factor Market Distortions across Time, Space, and Sectors in China, Review of Economic Dynamics 16(1), 39-58.

[46] Zhu, X-D., and T. Tombe, 2015, Trade, Migration and Productivity: A Quantitative Analysis of China, unpublished working paper, University of Toronto, Toronto. 


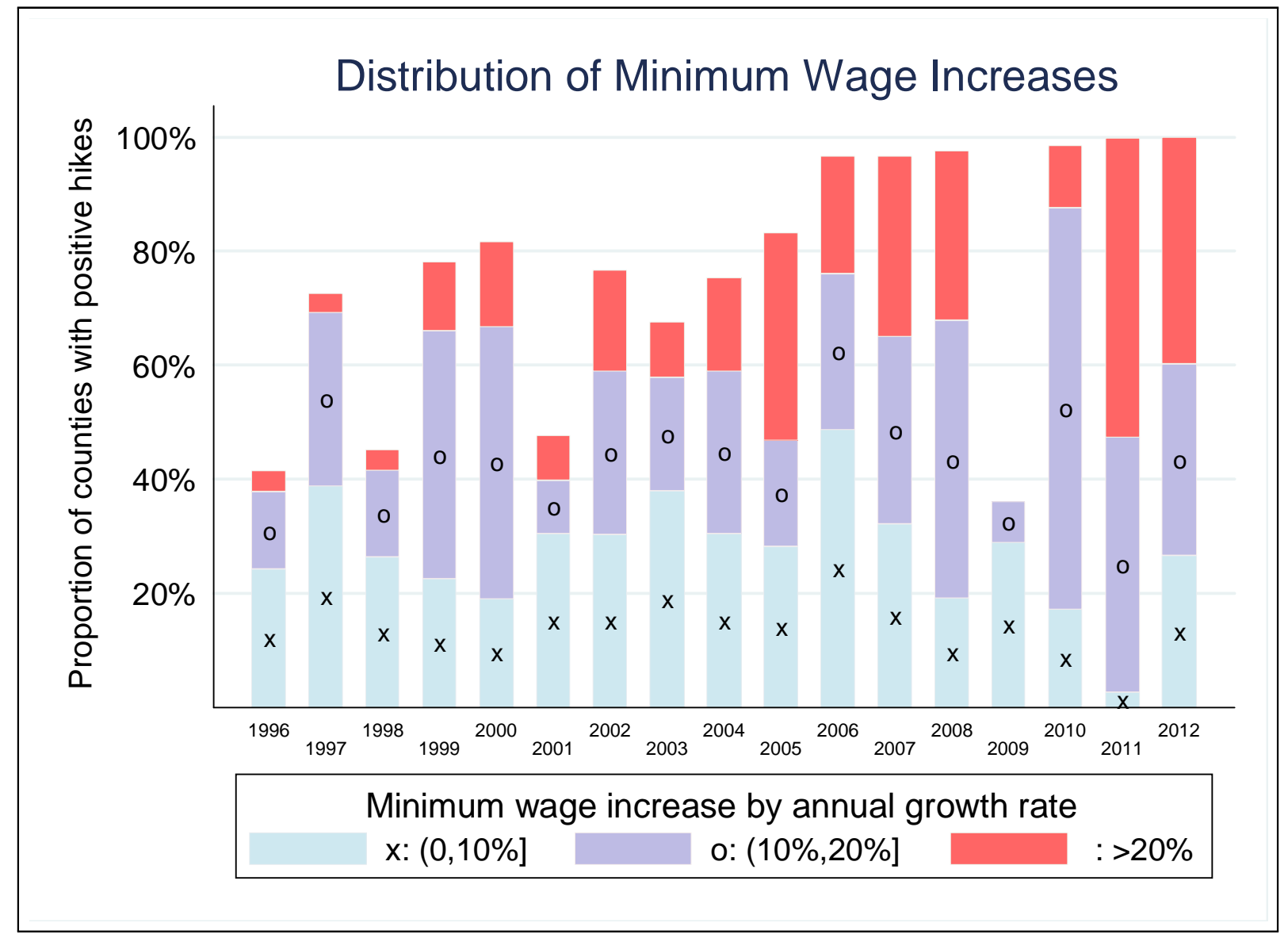

Figure 1: We plot by year the percentage of China's 2,867 counties and 333 cities with a strictly positive minimum wage change between 0 and $10 \%$, between $10 \%$ and $20 \%$, and above $20 \%$, respectively. 


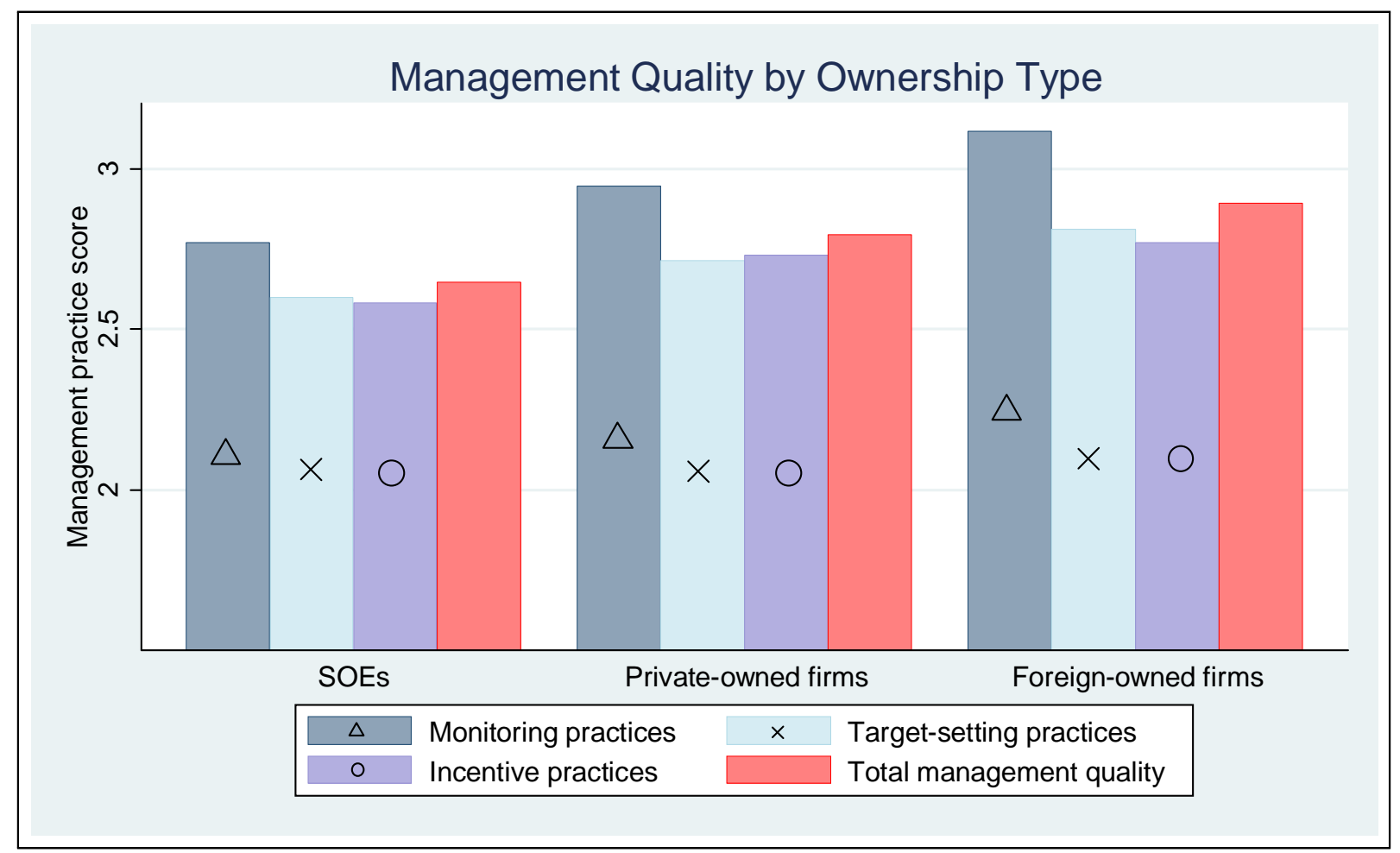

Figure 2: Based on survey data collected by Bloom and van Reenen (2010) on management practices in 564 Chinese firms sampled in 2006, 2007 and 2008, we report a breakdown of these scores by firm ownership (SOEs, private-owned firms, foreign-owned firms) after controlling for firm size and industry and year fixed effects. 


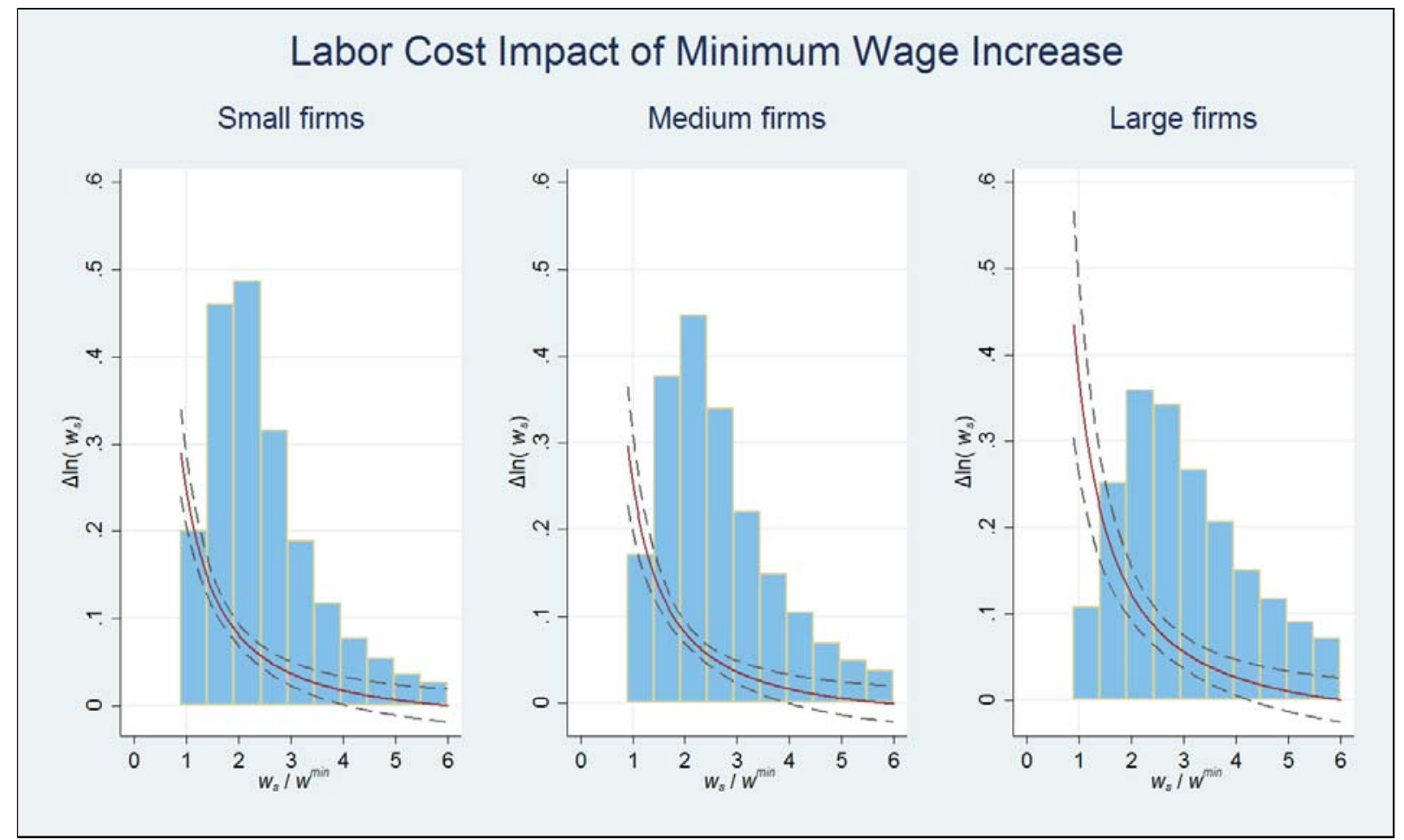

Figure 3: For small, medium, and large firms, we separately plot the estimated (nonlinear) average change in (log) firm wages $\Delta \ln w_{s}$ implied by a $22 \%$ minimum wage increase $\left[\Delta \ln \left(w^{\min }\right)=0.2\right]$ as a function of the ratio $w_{s} / w^{\min }$ of the average firm wage $w_{s}$ and the minimum wage $w^{\text {min }}$ in year $t-1$. The (background) histogram provides the firm distribution over the ratio $w_{s} / w^{\mathrm{min}}$. 


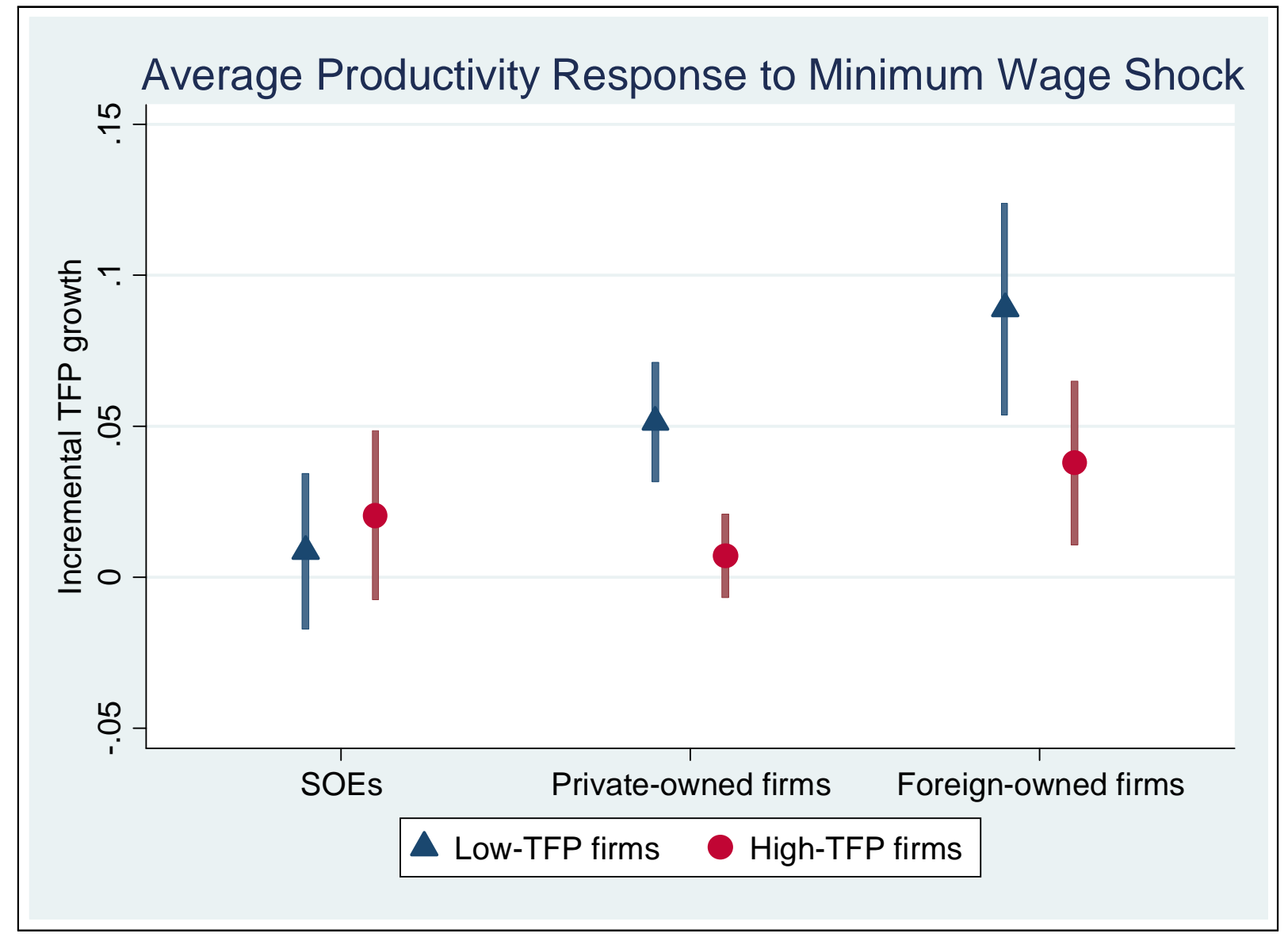

Figure 4: We plot the point estimate for the incremental TFP growth of a $22 \%\left[\Delta \ln \left(w^{\min }\right)=\right.$ 0.2 ] minimum wage increase on a low-wage firm (at the $10 \%$ quantile of its average firm wage relative to the local minimum wage) compared to a high-wage firm (at the $90 \%$ quantile) for firms of different ownership type (SOE, private-owned, foreign-owned) and below and above median TFP. 


\section{Table 1: Summary Statistics}

Panel A reports summary statistics for county-level (log) minimum wage changes for each year from 2002 to 2008 . Panel B describes the firm characteristics for the full firm sample, Panel C for state-owned enterprises (SOEs), Panel D for private-owned Chinese firms, and Panel E for foreignowned firms. Panels F and G sort firms in each industry into firms with TFP below and above the median at the beginning of the sample; we refer to them as low-TFP and high-TFP firms, respectively. For each firm sample, we reported (annual) changes in the (log) capital to labor ratio $\Delta \ln (K / N)$, changes in the (log) (value added) output $\Delta \ln (Y)$, changes in (log) labor input $\Delta \ln (N)$, changes in the (log) capital stock $\Delta \ln (K)$, and changes with respect to two measures of total factor productivity $\Delta \ln (A 1)$ and $\Delta \ln (A 2)$. Based on Chinese custom data, we also report in Panel $\mathrm{H}$ summary statistics on the value and volume of annual exports for all exporting firms.

\begin{tabular}{|c|c|c|c|c|c|c|c|c|}
\hline & Obs. & Mean & STD & Skew. & Kurt. & $\mathrm{P} 10$ & $\mathrm{P} 50$ & $\mathrm{P} 90$ \\
\hline \multicolumn{9}{|c|}{ Panel A: Minimun wage changes (in logs) $\Delta \ln w_{t}^{\min }$} \\
\hline 2002 & 2,807 & 0.101 & 0.095 & 0.974 & 3.517 & 0.000 & 0.091 & 0.258 \\
\hline 2003 & 2,809 & 0.064 & 0.069 & 1.038 & 3.519 & 0.000 & 0.048 & 0.170 \\
\hline 2004 & 2,825 & 0.097 & 0.092 & 0.808 & 2.925 & 0.000 & 0.080 & 0.235 \\
\hline 2005 & 2,821 & 0.131 & 0.103 & 0.699 & 3.662 & 0.000 & 0.118 & 0.255 \\
\hline 2006 & 2,829 & 0.105 & 0.087 & 0.885 & 3.057 & 0.013 & 0.090 & 0.240 \\
\hline 2007 & 2,772 & 0.143 & 0.091 & 0.680 & 2.886 & 0.035 & 0.118 & 0.281 \\
\hline 2008 & 2,785 & 0.150 & 0.076 & 0.818 & 3.828 & 0.063 & 0.134 & 0.244 \\
\hline All years & 19,648 & 0.113 & 0.093 & 0.781 & 3.320 & 0.000 & 0.097 & 0.240 \\
\hline \multicolumn{9}{|l|}{ Panel B: All firms } \\
\hline$\Delta \ln (K / N)$ & $1,192,144$ & 0.091 & 0.482 & 0.908 & 6.304 & -0.373 & 0.011 & 0.667 \\
\hline$\Delta \ln (Y)$ & $1,192,144$ & 0.175 & 0.630 & -0.056 & 4.387 & -0.566 & 0.173 & 0.922 \\
\hline$\Delta \ln (N)$ & $1,192,144$ & 0.028 & 0.302 & 0.301 & 6.197 & -0.288 & 0.000 & 0.372 \\
\hline$\Delta \ln (K)$ & $1,192,144$ & 0.119 & 0.434 & 1.672 & 8.947 & -0.125 & -0.010 & 0.623 \\
\hline$\Delta \ln (A 1)$ & $1,192,144$ & 0.123 & 0.627 & -0.081 & 4.201 & -0.631 & 0.128 & 0.870 \\
\hline$\Delta \ln (A 2)$ & $1,192,144$ & 0.125 & 0.623 & -0.068 & 4.214 & -0.622 & 0.128 & 0.869 \\
\hline$I F_{s} \times \Delta \ln w^{\min }$ & $1,192,144$ & 0.038 & 0.040 & 5.170 & 86.144 & 0.004 & 0.029 & 0.080 \\
\hline$\Delta \ln w^{\min }$ & $1,192,144$ & 0.110 & 0.072 & 0.759 & 4.057 & 0.019 & 0.102 & 0.211 \\
\hline$I F_{s}$ & $1,192,144$ & 0.361 & 0.277 & 4.774 & 51.573 & 0.119 & 0.311 & 0.629 \\
\hline$w_{s} / w^{\min }$ & $1,192,144$ & 2.900 & 1.844 & 3.065 & 19.067 & 1.423 & 2.394 & 4.878 \\
\hline \multicolumn{9}{|c|}{ Panel C: State-owned enterprises (SOEs) } \\
\hline$\Delta \ln (K / N)$ & 104,709 & 0.053 & 0.375 & 1.107 & 8.523 & -0.259 & -0.011 & 0.470 \\
\hline$\Delta \ln (Y)$ & 104,709 & 0.088 & 0.655 & -0.071 & 4.359 & -0.701 & 0.097 & 0.849 \\
\hline$\Delta \ln (N)$ & 104,709 & -0.024 & 0.239 & -0.188 & 9.380 & -0.246 & -0.005 & 0.177 \\
\hline$\Delta \ln (K)$ & 104,709 & 0.028 & 0.326 & 1.968 & 13.379 & -0.137 & -0.056 & 0.343 \\
\hline$\Delta \ln (A 1)$ & 104,709 & 0.094 & 0.659 & -0.062 & 4.210 & -0.706 & 0.105 & 0.866 \\
\hline$\Delta \ln (A 2)$ & 104,709 & 0.095 & 0.657 & -0.053 & 4.222 & -0.702 & 0.105 & 0.867 \\
\hline$I F_{s} \times \Delta \ln w^{\min }$ & 104,709 & 0.028 & 0.047 & 8.399 & 146.346 & 0.000 & 0.016 & 0.064 \\
\hline$\Delta \ln w^{\min }$ & 104,709 & 0.104 & 0.083 & 0.844 & 3.516 & 0.000 & 0.092 & 0.226 \\
\hline$I F_{s}$ & 104,709 & 0.294 & 0.353 & 5.589 & 50.385 & 0.074 & 0.201 & 0.568 \\
\hline$w_{s} / w^{\min }$ & 104,709 & 3.765 & 2.399 & 1.932 & 9.316 & 1.484 & 3.195 & 6.740 \\
\hline \multicolumn{9}{|c|}{ Panel D: Private-owned Chinese firms } \\
\hline$\Delta \ln (K / N)$ & 825,907 & 0.107 & 0.507 & 0.836 & 5.835 & -0.392 & 0.023 & 0.725 \\
\hline$\Delta \ln (Y)$ & 825,907 & 0.194 & 0.620 & -0.057 & 4.438 & -0.533 & 0.191 & 0.930 \\
\hline$\Delta \ln (N)$ & 825,907 & 0.032 & 0.310 & 0.333 & 6.026 & -0.288 & 0.000 & 0.394 \\
\hline$\Delta \ln (K)$ & 825,907 & 0.139 & 0.460 & 1.531 & 7.991 & -0.135 & 0.003 & 0.696 \\
\hline$\Delta \ln (A 1)$ & 825,907 & 0.133 & 0.620 & -0.093 & 4.212 & -0.614 & 0.139 & 0.872 \\
\hline$\Delta \ln (A 2)$ & 825,907 & 0.135 & 0.616 & -0.077 & 4.228 & -0.603 & 0.139 & 0.871 \\
\hline$I F_{s} \times \Delta \ln w^{\min }$ & 825,907 & 0.041 & 0.041 & 4.670 & 72.046 & 0.005 & 0.033 & 0.085 \\
\hline$\Delta \ln w^{\min }$ & 825,907 & 0.112 & 0.073 & 0.779 & 4.037 & 0.019 & 0.106 & 0.214 \\
\hline$I F_{s}$ & 825,907 & 0.385 & 0.271 & 4.680 & 51.065 & 0.147 & 0.337 & 0.651 \\
\hline$w_{s} / w^{\min }$ & 825,907 & 2.662 & 1.602 & 3.661 & 28.440 & 1.389 & 2.260 & 4.302 \\
\hline
\end{tabular}




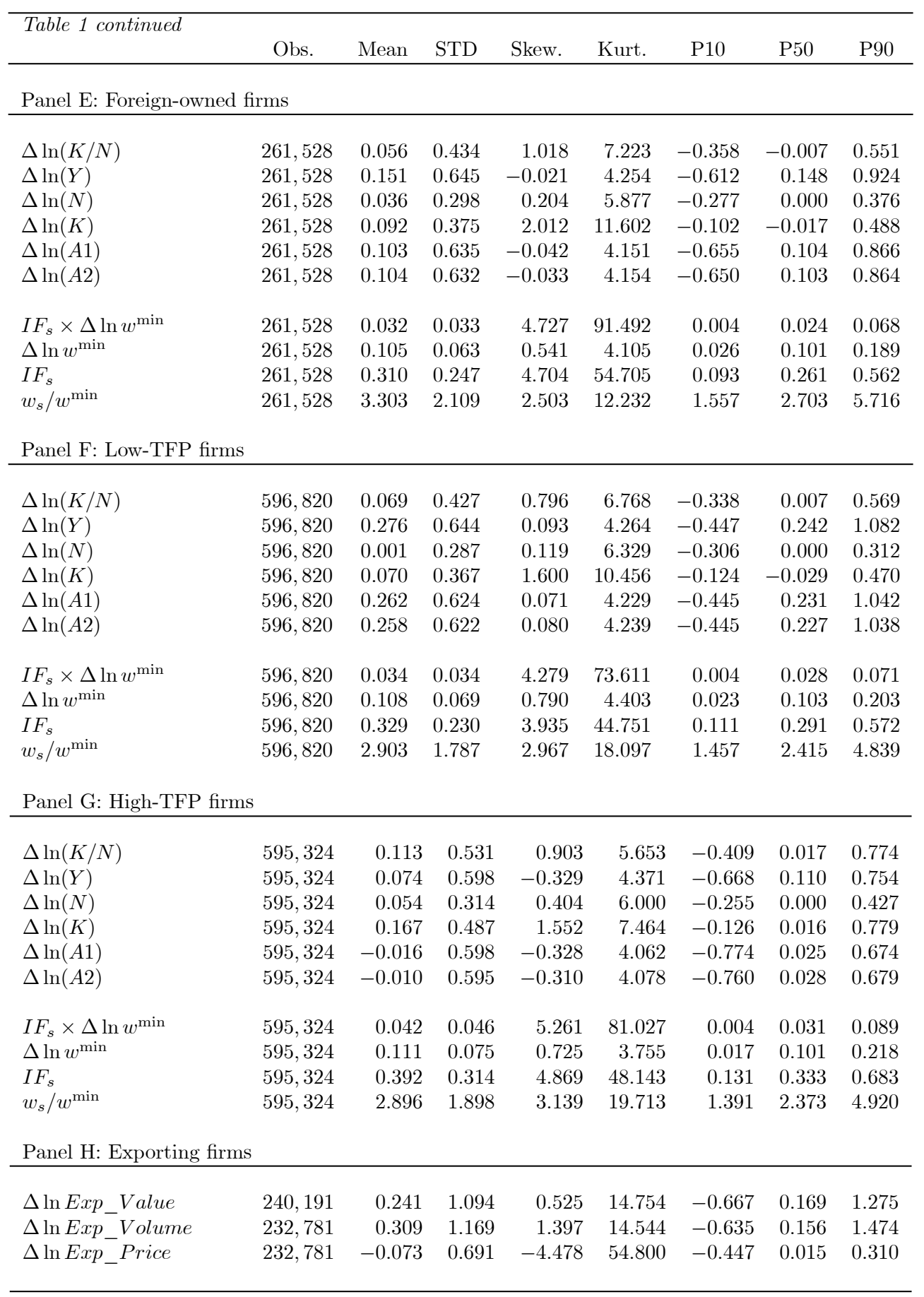




\section{Table 2: Non-Linear Firm Wage Impact of Minimum Wage Changes}

We estimate the non-linear effect of (log) minimum wage changes $\Delta \ln w^{\text {min }}$ on the (log) average yearly wage change $\Delta \ln w_{s}$ of industrial firms grouped into small, medium, and larger firms. To capture asymmetric exposure to minimum wage changes, we define a minimum wage impact function $I F_{s}(k)=\left(w_{s} / w^{\mathrm{min}}\right)^{-k}$ that depends on the ratio $w_{s} / w^{\mathrm{min}}$ of the firm average wage and the minimum wage and a parameter $k$ determining the convexity of the impact factor. The impact factor is interacted with the minimum wage changes. In order to estimate for the convexity parameter $k$, we first use in columns (1), (4), and (7) a maximum likelihood-based non-linear least square (NLLS) estimation based on wage changes $\Delta w_{s}$ in levels and county/city-level minimum wage changes $\Delta w^{\mathrm{min}}$ also in levels. Columns (2)-(3),(5)-(6), and (8)-(9) then use the implied impact factor $I F_{s}(k+1)$ for $\log$ changes. Columns (3), (6), and (9) augment the specification with firm fixed effects. All regressions control for interacted industry and year fixed effects. Reported are robust standard errors adjusted for clustering at the country-year unit in parenthesis and (block) bootstrapped standard errors in brackets based on 500 replications.

\begin{tabular}{|c|c|c|c|c|c|c|c|c|c|}
\hline & \multicolumn{3}{|c|}{ Small firms } & \multicolumn{3}{|c|}{ Medium firms } & \multicolumn{3}{|c|}{ Large firms } \\
\hline & $\begin{array}{c}\text { NLLS } \\
\Delta w_{s} \\
(1) \\
\end{array}$ & $\begin{array}{c}\mathrm{FE} \\
\Delta \ln w_{s} \\
(2)\end{array}$ & $\begin{array}{c}\mathrm{FE} \\
\Delta \ln w_{s} \\
(3)\end{array}$ & $\begin{array}{c}\text { NLLS } \\
\Delta w_{s} \\
(4) \\
\end{array}$ & $\begin{array}{c}\mathrm{FE} \\
\Delta \ln w_{s} \\
(5)\end{array}$ & $\begin{array}{c}\mathrm{FE} \\
\Delta \ln w_{s} \\
(6)\end{array}$ & $\begin{array}{c}\text { NLLS } \\
\Delta w_{s} \\
(7) \\
\end{array}$ & $\begin{array}{c}\mathrm{FE} \\
\Delta \ln w_{s} \\
(8)\end{array}$ & $\begin{array}{c}\mathrm{FE} \\
\Delta \ln w_{s} \\
(9) \\
\end{array}$ \\
\hline$k$ & $\begin{array}{r}0.373^{* * *} \\
(0.012)\end{array}$ & $k+1$ fixed & $k+1$ fixed & $\begin{array}{r}0.396^{* * *} \\
(0.019)\end{array}$ & $k+1$ fixed & $k+1$ fixed & $\begin{array}{r}0.361^{* * *} \\
(0.050)\end{array}$ & $k+1$ fixed & $k+1$ fixed \\
\hline$I F_{s}(k) \times \Delta w^{\min }$ & $\begin{array}{r}13.114^{* * *} \\
(0.412)\end{array}$ & & & $\begin{array}{r}11.871^{* * *} \\
(0.565)\end{array}$ & & & $\begin{array}{r}12.834^{* * *} \\
(1.714)\end{array}$ & & \\
\hline$I F_{s}(k)$ & $\begin{array}{r}4.196^{* * *} \\
(0.046)\end{array}$ & & & $\begin{array}{r}4.172^{* * *} \\
(0.078)\end{array}$ & & & $\begin{array}{r}4.340^{* * *} \\
(0.252)\end{array}$ & & \\
\hline$\Delta w^{\min }$ & $\begin{array}{r}-9.698^{* * *} \\
(0.392)\end{array}$ & & & $\begin{array}{r}-8.253^{* * *} \\
(0.529)\end{array}$ & & & $\begin{array}{r}-8.175^{* * *} \\
(1.607)\end{array}$ & & \\
\hline$I F_{s}(k+1) \times \Delta \ln w^{\min }$ & & $\begin{array}{r}0.771^{* * *} \\
(0.102) \\
{[0.100]}\end{array}$ & $\begin{array}{r}1.923^{* * *} \\
(0.206) \\
{[0.212]}\end{array}$ & & $\begin{array}{r}0.550^{* * *} \\
(0.118) \\
{[0.123]}\end{array}$ & $\begin{array}{r}1.864^{* * *} \\
(0.241) \\
{[0.272]}\end{array}$ & & $\begin{array}{r}0.886^{* * *} \\
(0.186) \\
{[0.223]}\end{array}$ & $\begin{array}{r}2.653^{* * *} \\
(0.363) \\
{[0.459]}\end{array}$ \\
\hline$I F(k+1)$ & & $\begin{array}{r}0.684^{* * *} \\
(0.012) \\
{[0.028]}\end{array}$ & $\begin{array}{r}1.262^{* * *} \\
(0.027) \\
{[0.083]}\end{array}$ & & $\begin{array}{r}0.662^{* * *} \\
(0.016) \\
{[0.029]}\end{array}$ & $\begin{array}{r}1.164^{* * *} \\
(0.037) \\
{[0.088]}\end{array}$ & & $\begin{array}{r}0.646^{* * *} \\
(0.029) \\
{[0.047]}\end{array}$ & $\begin{array}{r}1.350^{* * *} \\
(0.075) \\
{[0.174]}\end{array}$ \\
\hline$\Delta \ln w^{\min }$ & & $\begin{array}{r}0.072 \\
(0.051) \\
{[0.046]}\end{array}$ & $\begin{array}{r}-0.166^{* *} \\
(0.077) \\
{[0.082]}\end{array}$ & & $\begin{array}{c}0.101^{* *} \\
(0.047) \\
{[0.048]}\end{array}$ & $\begin{array}{r}-0.163^{* *} \\
(0.077) \\
{[0.090]}\end{array}$ & & $\begin{array}{r}0.051 \\
(0.068) \\
{[0.077]}\end{array}$ & $\begin{array}{r}-0.234^{* *} \\
(0.097) \\
{[0.115]}\end{array}$ \\
\hline Ind. $\times$ Time FE & Yes & Yes & Yes & Yes & Yes & Yes & Yes & Yes & Yes \\
\hline Firm FE & No & No & Yes & No & No & Yes & No & No & Yes \\
\hline Observations & 682,933 & 682,933 & 600,147 & 242,611 & 242,611 & 215,241 & 38,519 & 38,519 & 35,108 \\
\hline
\end{tabular}




\section{Table 3: Comparison of More and Less Treated Firms}

Firm observations in the same industry and year are divided into more exposed and less exposed firm with $I F_{s} \times \Delta \ln w^{\text {min }} \geq$ median and $I F_{s} \times$ $\Delta \ln w^{\text {min }} \leq$ median, respectively. In columns (1) and (2) we report for SOEs, the privately owned Chinese firms, and foreign owned firms the mean values of the $(\log )$ firm sales, the $(\log )$ employment $\ln (N)$, the $(\log )$ capital stock $\ln (K)$, the $(\log )$ capital to labor ratio $\ln (K / N)$, the firm profit margin (profit/sales), the (log) firm assets, and two measures of total factor productivity, $\ln (A 1)$ and $\ln (A 2)$, derived from a firm's cost share averaged over all years and the industry cost shares averaged over all firms for every year, respectively. We report in Column (4) a parametric t-test for the equality of the mean and in Column (5) the z-statistics for the non-parametric Wilcoxon test of equality of the two sample distributions. The sample period is 2002-08.

\begin{tabular}{|c|c|c|c|c|c|}
\hline & $\begin{array}{c}\text { Sample 1: } \\
\text { More Exposed } \\
I F_{s} \times \Delta \ln w^{\text {min }} \\
\geq \text { median } \\
\text { Mean } \\
\quad(1)\end{array}$ & $\begin{array}{l}\text { Sample 2: } \\
\text { Less Exposed } \\
I F_{s} \times \Delta \ln w^{\text {min }} \\
<\text { median } \\
\text { Mean } \\
(2) \\
\end{array}$ & $\begin{array}{c}\text { Difference (1)-(2) } \\
(3) \\
\end{array}$ & $\begin{array}{c}\begin{array}{c}\text { Equal mean } \\
\text { test }\end{array} \\
\\
T-\text { stat. } \\
(4)\end{array}$ & $\begin{array}{c}\begin{array}{c}\text { Wilcoxon } \\
\text { test }\end{array} \\
\begin{array}{c}\text { Z-stat. } \\
(5)\end{array}\end{array}$ \\
\hline \multicolumn{6}{|c|}{ State owned firms } \\
\hline $\begin{array}{l}\ln (\text { sales }) \\
\ln (N) \\
\ln (K) \\
\ln (K / N) \\
\text { profit margin } \\
\ln (\text { assets }) \\
\ln (A 1) \\
\ln (A 2)\end{array}$ & $\begin{array}{r}8.545 \\
5.493 \\
7.507 \\
2.014 \\
-0.037 \\
10.509 \\
0.682 \\
0.805\end{array}$ & $\begin{array}{r}9.166 \\
5.535 \\
7.878 \\
2.343 \\
-0.008 \\
10.975 \\
0.747 \\
0.879\end{array}$ & $\begin{array}{l}-0.621 \\
-0.042 \\
-0.372 \\
-0.329 \\
-0.028 \\
-0.466 \\
-0.065 \\
-0.074\end{array}$ & $\begin{array}{r}-49.858 \\
-4.751 \\
-28.935 \\
-42.839 \\
-24.067 \\
-39.414 \\
-9.302 \\
-10.546\end{array}$ & $\begin{array}{r}-48.758 \\
-2.691 \\
-27.164 \\
-42.783 \\
-34.450 \\
-37.486 \\
-11.943 \\
-13.423\end{array}$ \\
\hline \multicolumn{6}{|c|}{ Privately owned firms } \\
\hline $\begin{array}{l}\ln (\text { sales }) \\
\ln (N) \\
\ln (K) \\
\ln (K / N) \\
\text { profit margin } \\
\ln (\text { assets }) \\
\ln (A 1) \\
\ln (A 2)\end{array}$ & $\begin{array}{l}8.560 \\
4.649 \\
6.118 \\
1.469 \\
0.038 \\
9.429 \\
1.657 \\
1.782\end{array}$ & $\begin{array}{l}8.741 \\
4.602 \\
6.213 \\
1.611 \\
0.045 \\
9.520 \\
1.550 \\
1.690\end{array}$ & $\begin{array}{r}-0.181 \\
0.047 \\
-0.095 \\
-0.142 \\
-0.007 \\
-0.091 \\
0.107 \\
0.091\end{array}$ & $\begin{array}{r}-69.647 \\
21.839 \\
-30.151 \\
-55.926 \\
-41.761 \\
-33.455 \\
52.020 \\
45.382\end{array}$ & $\begin{array}{r}-74.776 \\
20.983 \\
-30.063 \\
-56.988 \\
-51.558 \\
-32.733 \\
47.223 \\
39.844\end{array}$ \\
\hline \multicolumn{6}{|c|}{ Foreign owned firms } \\
\hline $\begin{array}{l}\ln (\text { sales }) \\
\ln (N) \\
\ln (K) \\
\ln (K / N) \\
\text { profit margin } \\
\ln (\text { assets }) \\
\ln (A 1) \\
\ln (A 2)\end{array}$ & $\begin{array}{r}9.023 \\
5.305 \\
6.798 \\
1.492 \\
0.030 \\
10.146 \\
1.299 \\
1.433\end{array}$ & $\begin{array}{r}9.386 \\
5.103 \\
7.169 \\
2.066 \\
0.042 \\
10.504 \\
1.279 \\
1.419\end{array}$ & $\begin{array}{r}-0.362 \\
0.202 \\
-0.371 \\
-0.574 \\
-0.012 \\
-0.359 \\
0.020 \\
0.014\end{array}$ & $\begin{array}{r}-66.361 \\
46.605 \\
-58.729 \\
-107.755 \\
-28.679 \\
-66.587 \\
5.383 \\
3.950\end{array}$ & $\begin{array}{r}-65.709 \\
47.562 \\
-56.932 \\
-104.893 \\
-38.952 \\
-64.455 \\
0.193 \\
-1.433\end{array}$ \\
\hline
\end{tabular}




\section{Table 4: Labor to Capital Substitution and Minimum Wage Increases}

Reported are the estimated effects of minimum wage changes $\Delta \ln w^{\min }$ on yearly changes in the capital to labor ratio $\Delta \ln (K / N)_{s, t}$. The main specification features (1) an interaction terms of $I F_{s} \times \Delta \ln w^{\min }$ a firm's minimum wage impact function $I F(k)$ with the local minimum wage change $\Delta \ln w^{\min },(2)$ the minimum wage change $\Delta \ln w^{\min }$ itself and (3) the impact factor capturing a firm's (non-linear) sensitivity to minimum wage changes in a dynamic panel regression

$$
\Delta \ln (K / N)_{s, t}=\alpha \Delta \ln (K / N)_{s, t-1}+\beta\left[I F_{s} \times \Delta \ln w^{\min }\right]+\gamma I F_{s}+\delta \Delta \ln w^{\min }+\mu_{\text {Ind } \times Y e a r}+\nu_{s}+\epsilon_{s, t},
$$

where $\mu_{\text {Ind } \times \text { Year }}$ represents a set of interacted industry and year fixed effects. We report the least-square dummy variable regression (LSDV) in Column (1), and difference GMM results (DGMM) in all other columns that allow for firm fixed effects. Columns (3) and (4) extend the regression to triple interaction terms with either three different ownership dummies (SOE, private-owned, foreign-owned) or two firm productivity dummies for low- or high-TFP firms, respectively. Columns (8) and (9) report subsample regressions for SOEs and foreign owned firms, respectively. The minimum wage impact function $I F_{s}(k+1)=\left(w_{s} / w^{\min }\right)^{-(k+1)}$ depends on the ratio $w_{s} / w^{\text {min }}$ of a firm's average wage (in year $\left.t-1\right)$ relative to the the minimum wage $w^{\text {min }}$. The parameter $k$ determines the convexity of the impact factor function. We use $k+1=1.373,1.396$, and 1.361 obtained in Table 2 for small, medium, and large firms, respectively. The sample period is 2002-08. Reported are robust standard errors for the one-step estimator adjusted for clustering at the country-year unit in parenthesis and (block) bootstrapped standard errors in brackets to account for the first-stage estimation of the $I F_{s}$ term.

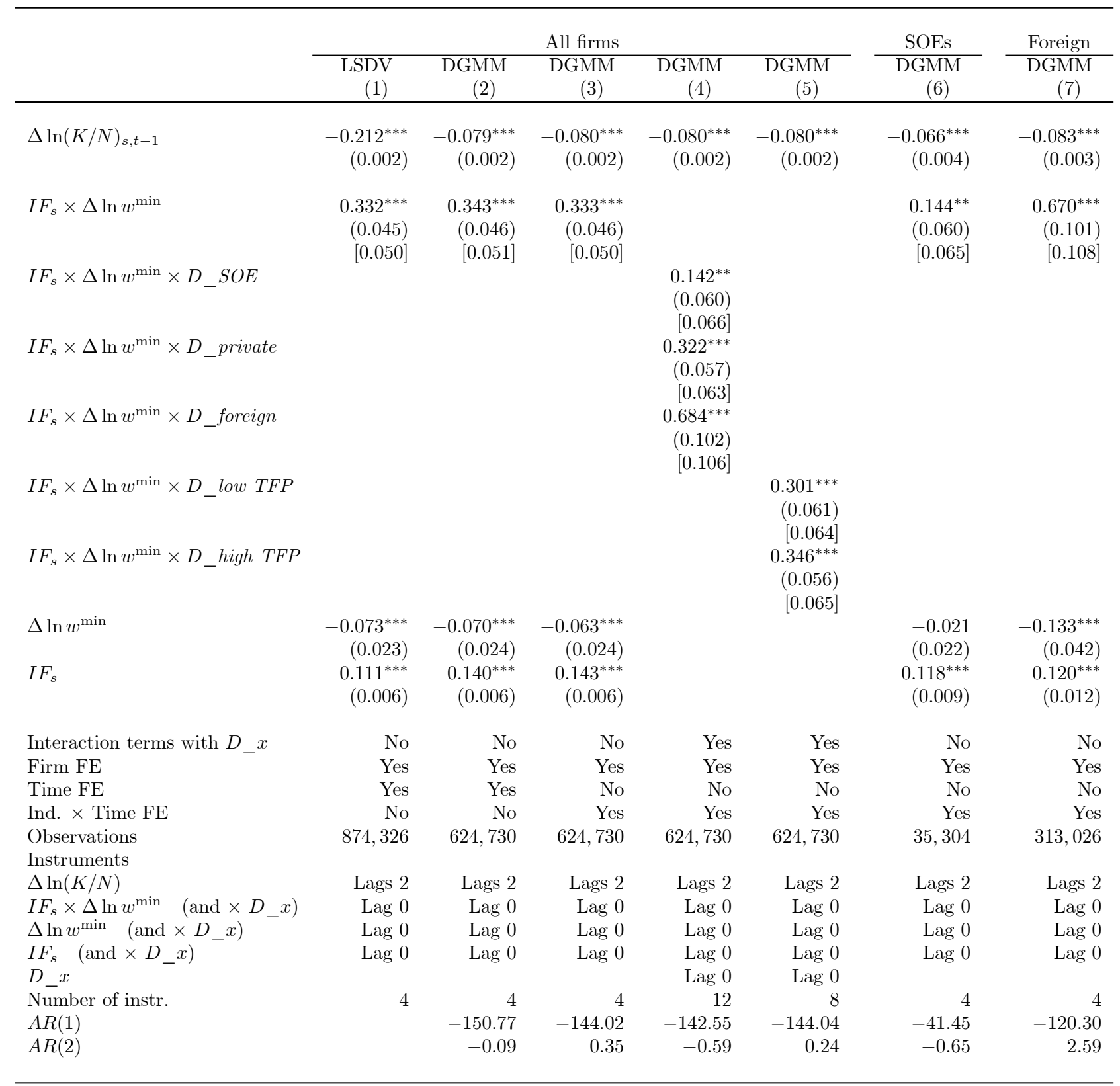


Table 5: The Production Response to Minimum Wage Increases

We report dynamic panel regressions in which output changes [columns (1)-(3)], labor input changes [columns (4)-(6)], capital input changes [columns (7)-(9)], and profitability [columns (10)-(12)] are explained by triple interaction terms $I F_{s} \times \Delta \ln w^{\min } \times D \_x$ of a firm's minimum wage impact function $I F_{s}$ and the local minimum wage changes $\Delta \ln w^{\mathrm{min}}$ and firm dummies $D_{-} x$, which can be either firm ownership dummies (SOE, privately owned, foreign owned) or productivity dummies (low-TFP, high-TFP). We include one lagged dependent variable in the following specification

$\Delta \ln Z_{s, t}=\alpha \Delta \ln Z_{s, t-1}+\sum_{x} \beta_{x}\left[I F_{s} \times \Delta \ln w^{\min } \times D \_x\right]+\sum_{x} \delta_{x}\left[\Delta \ln w^{\min } \times D \_x\right]+\sum_{x} \gamma_{x}\left[I F \times D \_x\right]+\sum_{x} \theta_{x} D \_x+\mu_{I n d \times Y e a r}+\nu_{s}+\epsilon_{s, t}$,

where $Z_{s}=Y_{s}, N_{s}, K_{s}, \Pi_{s}$ denote (value added) output, labor input (employment), capital, and profit, respectively. Reported are robust standard errors for the one-step estimator adjusted for clustering at the county/city-year unit in parenthesis and (block) bootstrapped standard errors in brackets to account for the first-stage estimation of the $I F$ term.

\begin{tabular}{|c|c|c|c|c|c|c|}
\hline & \multicolumn{3}{|c|}{ Output change $\Delta \ln Y_{s, t}$} & \multicolumn{3}{|c|}{ Labor input change $\Delta \ln N_{s}$} \\
\hline & $\begin{array}{l}\text { DGMM } \\
(1)\end{array}$ & $\begin{array}{c}\text { DGMM } \\
(2)\end{array}$ & $\begin{array}{c}\text { DGMM } \\
(3)\end{array}$ & $\begin{array}{c}\text { DGMM } \\
(4)\end{array}$ & $\begin{array}{c}\text { DGMM } \\
(5)\end{array}$ & $\begin{array}{c}\text { DGMM } \\
(6)\end{array}$ \\
\hline$\Delta \ln Z_{s, t-1}$ & $\begin{array}{r}-0.142^{* * *} \\
(0.001)\end{array}$ & $\begin{array}{r}-0.142^{* * *} \\
(0.003)\end{array}$ & $\begin{array}{r}-0.142^{* * *} \\
(0.003)\end{array}$ & $\begin{array}{r}-0.058^{* * *} \\
(0.001)\end{array}$ & $\begin{array}{r}-0.058^{* * *} \\
(0.002)\end{array}$ & $\begin{array}{r}-0.057^{* * *} \\
(0.002)\end{array}$ \\
\hline$I F_{s} \times \Delta \ln w^{\min }$ & $\begin{array}{r}0.137^{* * *} \\
(0.036) \\
{[0.059]}\end{array}$ & & & $\begin{array}{r}-0.193^{* * *} \\
(0.017) \\
{[0.043]}\end{array}$ & & \\
\hline$I F_{s} \times \Delta \ln w^{\min } \times D_{-} S O E$ & & $\begin{array}{r}0.051 \\
(0.086) \\
{[0.094]}\end{array}$ & & & $\begin{array}{r}-0.115^{* *} \\
(0.049) \\
{[0.053]}\end{array}$ & \\
\hline$I F_{s} \times \Delta \ln w^{\min } \times D \_$private & & $\begin{array}{c}0.120^{*} \\
(0.067) \\
{[0.071]}\end{array}$ & & & $\begin{array}{r}-0.179^{* * *} \\
(0.043) \\
{[0.051]}\end{array}$ & \\
\hline$I F_{s} \times \Delta \ln w^{\min } \times D \_$foreign & & $\begin{array}{r}0.408^{* * *} \\
(0.136) \\
{[0.158]}\end{array}$ & & & $\begin{array}{r}-0.406^{* * *} \\
(0.076) \\
{[0.090]}\end{array}$ & \\
\hline$I F_{s} \times \Delta \ln w^{\min } \times D_{-}$low TFP & & & $\begin{array}{c}0.168^{* *} \\
(0.086) \\
{[0.094]}\end{array}$ & & & $\begin{array}{r}-0.276^{* * *} \\
(0.051) \\
{[0.055]}\end{array}$ \\
\hline$I F_{s} \times \Delta \ln w^{\min } \times D_{-}$high TFP & & & $\begin{array}{r}0.096 \\
(0.060) \\
{[0.065]}\end{array}$ & & & $\begin{array}{r}-0.141^{* * *} \\
(0.039) \\
{[0.047]}\end{array}$ \\
\hline$\Delta \ln w^{\min }$ & $\begin{array}{l}-0.012 \\
(0.016)\end{array}$ & & & $\begin{array}{r}0.037^{* * *} \\
(0.008)\end{array}$ & & \\
\hline$I F_{s}$ & $\begin{array}{r}0.067^{* * *} \\
(0.005)\end{array}$ & & & $\begin{array}{r}-0.150^{* * *} \\
(0.002)\end{array}$ & & \\
\hline All interaction terms with $D x$ & No & Yes & Yes & No & Yes & Yes \\
\hline Firm FE & Yes & Yes & Yes & Yes & Yes & Yes \\
\hline Ind. $\mathrm{FE} \times$ Time $\mathrm{FE}$ & Yes & Yes & Yes & Yes & Yes & Yes \\
\hline $\begin{array}{l}\text { Observations } \\
\text { Instruments }\end{array}$ & 616,800 & 616,800 & 616,800 & 625,549 & 625,549 & 625,549 \\
\hline$\Delta \ln Z$ & Lag 2 & Lag 2 & Lag 2 & Lag 2 & Lag 2 & Lag 2 \\
\hline$I F_{s} \times \Delta \ln w^{\min } \quad\left(\right.$ and $\left.\times D_{-} x\right)$ & Lag 0 & Lag 0 & Lag 0 & Lag 0 & Lag 0 & Lag 0 \\
\hline$\Delta \ln w^{\min } \quad\left(\right.$ and $\left.\times D \_x\right)$ & Lag 0 & Lag 0 & Lag 0 & Lag 0 & Lag 0 & Lag 0 \\
\hline$I F_{s} \quad\left(\right.$ and $\left.\times D_{-} x\right)$ & Lag 0 & Lag 0 & Lag 0 & Lag 0 & Lag 0 & Lag 0 \\
\hline$D_{-} x$ & & Lag 0 & Lag 0 & & Lag 0 & Lag 0 \\
\hline Nümber of instruments & 4 & 12 & 8 & 4 & 12 & 8 \\
\hline$A R(1)$ & -281.34 & -124.80 & -124.68 & -276.57 & -128.31 & -128.25 \\
\hline$A R(2)$ & -3.43 & -2.80 & -2.76 & 7.51 & 6.42 & 6.40 \\
\hline
\end{tabular}




\begin{tabular}{|c|c|c|c|c|c|c|}
\hline \multirow{2}{*}{ Table 5 continued } & \multicolumn{3}{|c|}{ Capital input change $\Delta \ln K_{s, t}$} & \multicolumn{3}{|c|}{ Profit margin change } \\
\hline & $\begin{array}{c}\text { DGMM } \\
(7)\end{array}$ & $\begin{array}{c}\text { DGMM } \\
(8)\end{array}$ & $\begin{array}{c}\text { DGMM } \\
(9)\end{array}$ & $\begin{array}{c}\text { DGMM } \\
(10)\end{array}$ & $\begin{array}{c}\text { DGMM } \\
(11)\end{array}$ & $\begin{array}{c}\text { DGMM } \\
(12)\end{array}$ \\
\hline$\Delta \ln Z_{s, t-1}$ & $\begin{array}{r}-0.051^{* * *} \\
(0.001)\end{array}$ & $\begin{array}{r}-0.051^{* * *} \\
(0.002)\end{array}$ & $\begin{array}{r}-0.051^{* * *} \\
(0.002)\end{array}$ & $\begin{array}{r}-0.198^{* * *} \\
(0.001)\end{array}$ & $\begin{array}{r}-0.216^{* * *} \\
(0.005)\end{array}$ & $\begin{array}{r}-0.198^{* * *} \\
(0.004)\end{array}$ \\
\hline$I F_{s} \times \Delta \ln w^{\min }$ & $\begin{array}{r}0.142^{* * *} \\
(0.024) \\
{[0.039]}\end{array}$ & & & $\begin{array}{r}0.019^{* * *} \\
(0.005) \\
{[0.009]}\end{array}$ & & \\
\hline$I F_{s} \times \Delta \ln w^{\min } \times D_{-} S O E$ & & $\begin{array}{r}0.026 \\
(0.043) \\
{[0.050]}\end{array}$ & & & $\begin{array}{c}-0.043 \\
(0.030) \\
{[0.026]}\end{array}$ & \\
\hline$I F_{s} \times \Delta \ln w^{\min } \times D_{-}$private & & $\begin{array}{r}0.146^{* * *} \\
(0.047) \\
{[0.050]}\end{array}$ & & & $\begin{array}{r}0.031^{* * *} \\
(0.010) \\
{[0.009]}\end{array}$ & \\
\hline$I F_{s} \times \Delta \ln w^{\min } \times D \_$foreign & & $\begin{array}{r}0.284^{* * *} \\
(0.081) \\
{[0.090]}\end{array}$ & & & $\begin{array}{r}0.030 \\
(0.020) \\
{[0.023]}\end{array}$ & \\
\hline$I F_{s} \times \Delta \ln w^{\min } \times D_{-}$low TFP & & & $\begin{array}{r}0.031 \\
(0.038) \\
{[0.041]}\end{array}$ & & & $\begin{array}{r}0.015 \\
(0.015) \\
{[0.016]}\end{array}$ \\
\hline$I F_{s} \times \Delta \ln w^{\min } \times D_{-}$high TFP & & & $\begin{array}{r}0.205^{* * *} \\
(0.048) \\
{[0.056]}\end{array}$ & & & $\begin{array}{c}0.015^{*} \\
(0.009) \\
{[0.009]}\end{array}$ \\
\hline$\Delta \ln w^{\min }$ & $\begin{array}{r}-0.026^{* *} \\
(0.011)\end{array}$ & & & $\begin{array}{r}0.001 \\
(0.002)\end{array}$ & & \\
\hline$I F_{s}$ & $\begin{array}{l}-0.003 \\
(0.003)\end{array}$ & & & $\begin{array}{r}0.003^{* * *} \\
(0.001)\end{array}$ & & \\
\hline All interaction terms with $D_{-} x$ & No & Yes & Yes & Yes & Yes & Yes \\
\hline Firm FE & Yes & Yes & Yes & Yes & Yes & Yes \\
\hline Ind. $\mathrm{FE} \times$ Time $\mathrm{FE}$ & Yes & Yes & Yes & Yes & Yes & Yes \\
\hline $\begin{array}{l}\text { Observations } \\
\text { Instruments }\end{array}$ & 624,730 & 624,730 & 624,730 & 624,730 & & \\
\hline$\Delta \ln Z$ & Lag 2 & Lag 2 & Lag 2 & Lag 2 & Lag 2 & Lag 2 \\
\hline$I F_{s} \times \Delta \ln w^{\min } \quad\left(\right.$ and $\left.\times D_{-} x\right)$ & Lag 0 & Lag 0 & Lag 0 & Lag 0 & Lag 0 & Lag 0 \\
\hline$\Delta \ln w^{\min } \quad\left(\text { and } \times D \_x\right)^{-}$ & Lag 0 & Lag 0 & Lag 0 & Lag 0 & Lag 0 & Lag 0 \\
\hline$I F_{s} \quad\left(\right.$ and $\left.\times D_{-} x\right)$ & Lag 0 & Lag 0 & Lag 0 & Lag 0 & Lag 0 & Lag 0 \\
\hline$D \_x$ & & Lag 0 & Lag 0 & & Lag 0 & Lag 0 \\
\hline Number of instruments & 4 & 12 & 8 & 4 & 12 & 8 \\
\hline$A R(1)$ & -267.26 & -125.74 & -125.75 & -296.21 & -66.42 & -68.59 \\
\hline$A R(2)$ & 3.72 & 3.38 & 3.40 & -18.73 & -10.81 & -8.18 \\
\hline
\end{tabular}




\section{Table 6: Total Factor Productivity Growth after Minimum Wage Increases}

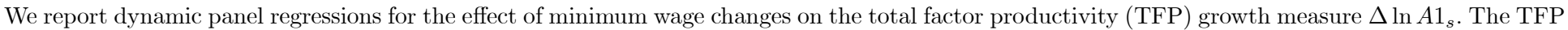

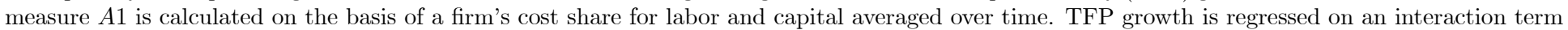

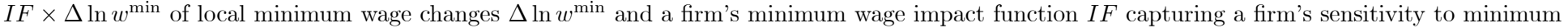
wage increases. The regressors include the lagged dependent variable, the level effects $\Delta \ln w^{\text {min }}$, and $I F$ in the following specification

$$
\Delta \ln A 1_{s, t}=\alpha \Delta \ln A 1_{s, t-1}+\beta\left[I F_{s} \times \Delta \ln w^{\min }\right]+\gamma I F_{s}+\delta \Delta \ln w^{\min }+\mu_{I n d \times Y e a r}+\nu_{s}+\epsilon_{s, t} .
$$

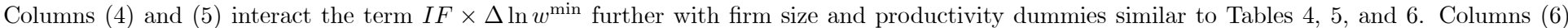

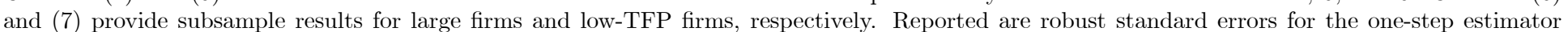

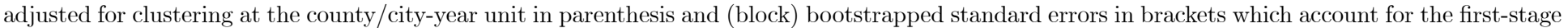
estimation of the $I F$ term.

\begin{tabular}{|c|c|c|c|c|c|c|c|}
\hline & \multicolumn{5}{|c|}{ All firms } & \multirow{2}{*}{$\begin{array}{c}\text { SOEs } \\
\text { DGMM } \\
(6)\end{array}$} & \multirow{2}{*}{$\begin{array}{c}\text { Foreign } \\
\text { DGMM } \\
(7)\end{array}$} \\
\hline & $\begin{array}{r}\text { LSDV } \\
(1) \\
\end{array}$ & $\begin{array}{c}\text { DGMM } \\
(2) \\
\end{array}$ & $\begin{array}{c}\text { DGMM } \\
(3) \\
\end{array}$ & $\begin{array}{c}\text { DGMM } \\
(4) \\
\end{array}$ & $\begin{array}{c}\text { DGMM } \\
(5) \\
\end{array}$ & & \\
\hline$\Delta \ln A 1_{s, t-1}$ & $\begin{array}{r}-0.284^{* * *} \\
(0.003)\end{array}$ & $\begin{array}{r}-0.147^{* * *} \\
(0.003)\end{array}$ & $\begin{array}{r}-0.156^{* * *} \\
(0.003)\end{array}$ & $\begin{array}{r}-0.156^{* * *} \\
(0.003)\end{array}$ & $\begin{array}{r}-0.156^{* * *} \\
(0.003)\end{array}$ & $\begin{array}{r}-0.164^{* * *} \\
(0.004)\end{array}$ & $\begin{array}{r}-0.165^{* * *} \\
(0.005)\end{array}$ \\
\hline$I F_{s} \times \Delta \ln w^{\min }$ & $\begin{array}{r}0.228^{* * *} \\
(0.064) \\
{[0.070]}\end{array}$ & $\begin{array}{r}0.244^{* * *} \\
(0.062) \\
{[0.071]}\end{array}$ & $\begin{array}{r}0.234^{* * *} \\
(0.061) \\
{[0.071]}\end{array}$ & & & $\begin{array}{r}0.139 \\
(0.092) \\
{[0.104]}\end{array}$ & $\begin{array}{r}0.601^{\text {*** }} \\
(0.147) \\
{[0.169]}\end{array}$ \\
\hline$I F_{s} \times \Delta \ln w^{\min } \times D_{-} S O E$ & & & & $\begin{array}{r}0.122 \\
(0.092) \\
{[0.104]}\end{array}$ & & & \\
\hline$I F_{s} \times \Delta \ln w^{\min } \times D_{-}$private & & & & $\begin{array}{c}0.198 * * \\
(0.077) \\
{[0.086]}\end{array}$ & & & \\
\hline$I F_{s} \times \Delta \ln w^{\min } \times D_{\text {_foreign }}$ & & & & $\begin{array}{r}0.669^{* * *} \\
(0.148) \\
{[0.174]}\end{array}$ & & & \\
\hline$I F_{s} \times \Delta \ln w^{\min } \times D_{-}$low TFP & & & & & $\begin{array}{r}0.372^{\text {*** }} \\
(0.100) \\
{[0.106]}\end{array}$ & & \\
\hline$I F_{s} \times \Delta \ln w^{\min } \times D_{-}$high TFP & & & & & $\begin{array}{c}0.127^{*} \\
(0.066) \\
{[0.075]}\end{array}$ & & \\
\hline$\Delta \ln w^{\min }$ & $\begin{array}{r}-0.065^{*} \\
(0.033)\end{array}$ & $\begin{array}{l}-0.051 \\
(0.033)\end{array}$ & $\begin{array}{l}-0.032 \\
(0.032)\end{array}$ & & & $\begin{array}{r}0.046 \\
(0.039)\end{array}$ & $\begin{array}{l}-0.067 \\
(0.066)\end{array}$ \\
\hline$I F_{s}$ & $\begin{array}{r}0.136^{* * *} \\
(0.008)\end{array}$ & $\begin{array}{r}0.166^{* * *} \\
(0.008)\end{array}$ & $\begin{array}{r}0.165^{* * *} \\
(0.008)\end{array}$ & & & $\begin{array}{r}0.117^{* * *} \\
(0.014)\end{array}$ & $\begin{array}{r}0.189^{* * *} \\
(0.018)\end{array}$ \\
\hline All interaction terms with $D_{-} x$ & No & Yes & Yes & Yes & Yes & Nos & No \\
\hline Firm FE & Yes & Yes & Yes & Yes & Yes & Yes & Yes \\
\hline Time FE & Yes & Yes & No & No & No & No & No \\
\hline Ind. $\mathrm{FE} \times$ Time $\mathrm{FE}$ & No & No & Yes & Yes & Yes & Yes & Yes \\
\hline $\begin{array}{l}\text { Observations } \\
\text { Instruments }\end{array}$ & 861,284 & 615,992 & 615,992 & 615,992 & 615,992 & 34,876 & 307,396 \\
\hline$\Delta \ln A 1$ & Lag 2 & Lag 2 & Lag 2 & Lag 2 & Lag 2 & Lag 2 & Lag 2 \\
\hline$I F_{s} \times \Delta \ln w^{\min } \quad\left(\right.$ and $\left.\times D_{-} x\right)$ & Lag 0 & Lag 0 & Lag 0 & Lag 0 & Lag 0 & Lag 0 & Lag 0 \\
\hline$\Delta \ln w^{\min } \quad\left(\right.$ and $\left.\times D_{-} x\right)$ & Lag 0 & Lag 0 & Lag 0 & Lag 0 & Lag 0 & Lag 0 & Lag 0 \\
\hline $\begin{array}{l}I F_{s} \quad\left(\text { and } \times D_{-} x\right) \\
D_{x}\end{array}$ & Lag 0 & Lag 0 & Lag 0 & $\begin{array}{l}\text { Lag } 0 \\
\text { Lag } 0\end{array}$ & $\begin{array}{l}\text { Lag } 0 \\
\text { Lag } 0\end{array}$ & Lag 0 & Lag 0 \\
\hline Nümber of instruments & 4 & 4 & 4 & 12 & 8 & 4 & 4 \\
\hline$A R(1)$ & & -127.07 & -129.73 & -129.22 & -135.97 & -41.85 & -108.39 \\
\hline$A R(2)$ & & -5.95 & -4.19 & -4.43 & -1.21 & -3.03 & -6.41 \\
\hline
\end{tabular}


Table 7: Productivity Effect by Ownership Type

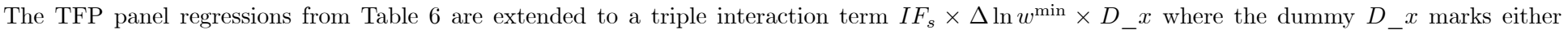

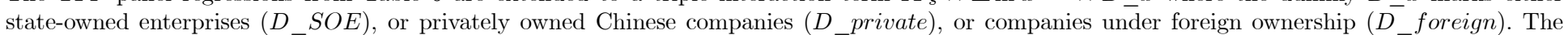

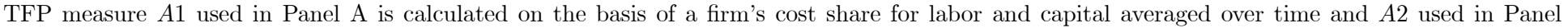

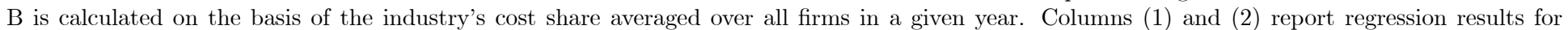

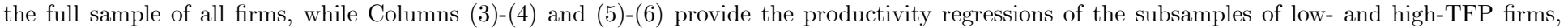

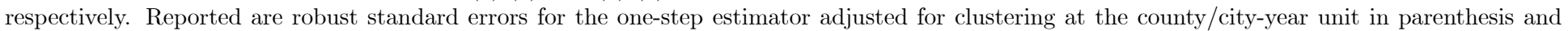
(block) bootstrapped standard errors in brackets which account for the first-stage estimation of the $I F$ term.

\begin{tabular}{|c|c|c|c|c|c|c|}
\hline \multicolumn{7}{|c|}{ Panel A: TFP growth $\Delta \ln A 1_{s, t}$} \\
\hline & \multicolumn{2}{|c|}{ All firms } & \multicolumn{2}{|c|}{ Low-TFP firms } & \multicolumn{2}{|c|}{ High-TFP firms } \\
\hline & $\begin{array}{c}\text { DGMM } \\
(1) \\
\end{array}$ & $\begin{array}{c}\text { DGMM } \\
(2) \\
\end{array}$ & $\begin{array}{c}\text { DGMM } \\
(3) \\
\end{array}$ & $\begin{array}{c}\text { DGMM } \\
(4) \\
\end{array}$ & $\begin{array}{c}\text { DGMM } \\
(5) \\
\end{array}$ & $\begin{array}{c}\text { DGMM } \\
(6) \\
\end{array}$ \\
\hline $\ln A_{s, t-1}$ & $\begin{array}{r}-0.147^{* * *} \\
(0.003)\end{array}$ & $\begin{array}{r}-0.156^{* * *} \\
(0.003)\end{array}$ & $\begin{array}{r}-0.163^{* * *} \\
(0.003)\end{array}$ & $\begin{array}{r}-0.172^{\text {*** }} \\
(0.003)\end{array}$ & $\begin{array}{r}-0.131^{* * *} \\
(0.003)\end{array}$ & $\begin{array}{r}-0.140^{* * *} \\
(0.003)\end{array}$ \\
\hline \multirow[t]{3}{*}{$I F_{s} \times \Delta \ln w^{\min } \times D_{-} S O E$} & 0.144 & 0.122 & 0.143 & 0.103 & 0.203 & 0.196 \\
\hline & $(0.094)$ & $(0.092)$ & $(0.133)$ & $(0.132)$ & $(0.124)$ & $(0.122)$ \\
\hline & {$[0.103]$} & {$[0.104]$} & {$[0.141]$} & {$[0.142]$} & {$[0.140]$} & {$[0.144]$} \\
\hline \multirow{3}{*}{$I F_{s} \times \Delta \ln w^{\min } \times D_{\text {_p private }}$} & $0.214^{* * *}$ & $0.198^{* *}$ & 0.192 & 0.190 & $0.181^{* *}$ & $0.154^{*}$ \\
\hline & $(0.078)$ & $(0.077)$ & $(0.149)$ & $(0.148)$ & $(0.082)$ & $(0.080)$ \\
\hline & {$[0.086]$} & {$[0.086]$} & {$[0.155]$} & {$[0.156]$} & {$[0.090]$} & {$[0.088]$} \\
\hline \multirow{3}{*}{$I F_{s} \times \Delta \ln w^{\min } \times D_{-}$foreign } & $0.707^{* * *}$ & $0.669^{* * *}$ & $1.494^{* * *}$ & $1.439^{* * *}$ & 0.235 & 0.199 \\
\hline & $(0.157)$ & $(0.148)$ & $(0.270)$ & $(0.250)$ & $(0.160)$ & $(0.156)$ \\
\hline & {$[0.176]$} & {$[0.174]$} & {$[0.235]$} & {$[0.234]$} & {$[0.195]$} & {$[0.190]$} \\
\hline All other (interaction) terms & Yes & Yes & Yes & Yes & Yes & Yes \\
\hline Firm FE & Yes & Yes & Yes & Yes & Yes & Yes \\
\hline Time FE & Yes & Yes & Yes & Yes & Yes & Yes \\
\hline Ind. $\mathrm{FE} \times$ Time $\mathrm{FE}$ & No & Yes & No & Yes & No & Yes \\
\hline \multirow[t]{4}{*}{ Observations } & 638,582 & 638,582 & 317,058 & 317,058 & 321,524 & 321,524 \\
\hline & \multicolumn{4}{|c|}{ Panel B: TFP growth $\Delta \ln A 2_{s, t}$} & & \\
\hline & \multicolumn{2}{|c|}{ All firms } & \multicolumn{2}{|c|}{ Low-TFP firms } & \multicolumn{2}{|c|}{ High-TFP firms } \\
\hline & $\begin{array}{c}\text { DGMM } \\
(1) \\
\end{array}$ & $\begin{array}{c}\text { DGMM } \\
(2) \\
\end{array}$ & $\begin{array}{c}\text { DGMM } \\
(3) \\
\end{array}$ & $\begin{array}{c}\text { DGMM } \\
(4) \\
\end{array}$ & $\begin{array}{c}\text { DGMM } \\
(5) \\
\end{array}$ & $\begin{array}{c}\text { DGMM } \\
(6) \\
\end{array}$ \\
\hline$\Delta \ln A 2_{s, t-1}$ & $\begin{array}{r}-0.148^{* * *} \\
(0.003)\end{array}$ & $\begin{array}{r}-0.156^{* * *} \\
(0.003)\end{array}$ & $\begin{array}{r}-0.165^{* * *} \\
(0.003)\end{array}$ & $\begin{array}{r}-0.174^{* * *} \\
(0.003)\end{array}$ & $\begin{array}{r}-0.130^{* * *} \\
(0.003)\end{array}$ & $\begin{array}{r}-0.139^{* * *} \\
(0.003)\end{array}$ \\
\hline \multirow[t]{3}{*}{$I F_{s} \times \Delta \ln w^{\min } \times D_{-} S O E$} & 0.139 & 0.117 & 0.118 & 0.077 & $0.227^{*}$ & $0.219^{*}$ \\
\hline & $(0.095)$ & $(0.093)$ & $(0.132)$ & $(0.131)$ & $(0.127)$ & $(0.125)$ \\
\hline & {$[0.104]$} & {$[0.105]$} & {$[0.143]$} & {$[0.144]$} & {$[0.144]$} & {$[0.147]$} \\
\hline \multirow{3}{*}{$I F_{s} \times \Delta \ln w^{\min } \times D_{-}$Private } & $0.229^{* * *}$ & $0.213^{* * *}$ & 0.192 & 0.190 & $0.206^{* *}$ & $0.179^{* *}$ \\
\hline & $(0.077)$ & $(0.076)$ & $(0.148)$ & $(0.147)$ & $(0.081)$ & $(0.079)$ \\
\hline & {$[0.086]$} & {$[0.085]$} & {$[0.153]$} & {$[0.154]$} & {$[0.090]$} & {$[0.087]$} \\
\hline \multirow{3}{*}{$I F_{s} \times \Delta \ln w^{\min } \times D_{-}$Foreign } & $0.696^{* * *}$ & $0.657^{* * *}$ & $1.455^{* * *}$ & $1.399^{* * *}$ & 0.241 & 0.204 \\
\hline & $(0.156)$ & $(0.148)$ & $(0.268)$ & $(0.248)$ & $(0.161)$ & $(0.157)$ \\
\hline & {$[0.176]$} & {$[0.173]$} & {$[0.231]$} & {$[0.231]$} & {$[0.197]$} & {$[0.192]$} \\
\hline All other (interaction) terms & Yes & Yes & Yes & Yes & Yes & Yes \\
\hline Firm FE & Yes & Yes & Yes & Yes & Yes & Yes \\
\hline Time FE & Yes & Yes & Yes & Yes & Yes & Yes \\
\hline Ind. $\mathrm{FE} \times$ Time $\mathrm{FE}$ & No & Yes & No & Yes & No & Yes \\
\hline Observations & 638,582 & 638,582 & 317,058 & 317,058 & 321,524 & 321,524 \\
\hline
\end{tabular}




\section{Table 8: Productivity Effect by Management Practice}

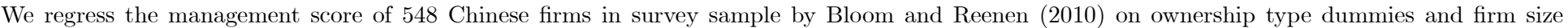

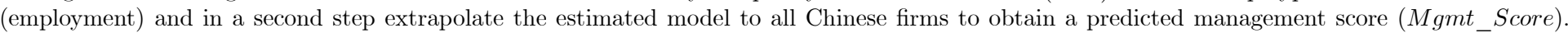

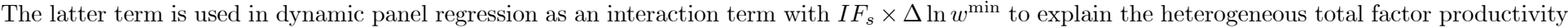

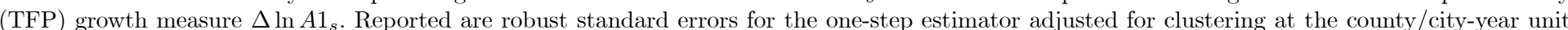
in parenthesis and (block) bootstrapped standard errors in brackets which account for the first-stage estimation of the $M g m t \_S c o r e ~ t e r m$.

\begin{tabular}{|c|c|c|c|c|c|c|}
\hline & \multicolumn{2}{|c|}{ All firms } & \multicolumn{2}{|c|}{ Low-TFP firms } & \multicolumn{2}{|c|}{ High-TFP firms } \\
\hline & $\begin{array}{c}\text { DGMM } \\
(1)\end{array}$ & $\begin{array}{c}\text { DGMM } \\
(2)\end{array}$ & $\begin{array}{c}\text { DGMM } \\
(3)\end{array}$ & $\begin{array}{c}\text { DGMM } \\
(4)\end{array}$ & $\begin{array}{c}\text { DGMM } \\
(5)\end{array}$ & $\begin{array}{c}\text { DGMM } \\
(6)\end{array}$ \\
\hline$\Delta \ln A 1_{s, t-1}$ & $\begin{array}{r}-0.148^{* * *} \\
(0.003)\end{array}$ & $\begin{array}{r}-0.156^{* * *} \\
(0.003)\end{array}$ & $\begin{array}{r}-0.163^{* * *} \\
(0.003)\end{array}$ & $\begin{array}{r}-0.172^{* * *} \\
(0.003)\end{array}$ & $\begin{array}{r}-0.132^{\text {*** }} \\
(0.003)\end{array}$ & $\begin{array}{r}-0.140^{* * *} \\
(0.003)\end{array}$ \\
\hline$I F_{s} \times \Delta \ln w^{\min } \times M g m t \quad$ Score & $0.436^{*}$ & $0.518^{* *}$ & $1.336^{* * *}$ & $1.368^{* * *}$ & -0.103 & 0.034 \\
\hline & $(0.260)$ & $(0.250)$ & $(0.482)$ & $(0.469)$ & $(0.279)$ & $(0.271)$ \\
\hline & {$[0.294]$} & {$[0.290]$} & {$[0.524]$} & {$[0.521]$} & {$[0.322]$} & 0.313 \\
\hline$\Delta \ln w^{\min } \times$ Mgmt_Score & -0.048 & -0.056 & $-0.352^{* *}$ & $-0.311^{* *}$ & 0.133 & 0.086 \\
\hline & $(0.111)$ & $(0.109)$ & $(0.158)$ & $(0.155)$ & $(0.132)$ & $(0.129)$ \\
\hline & {$[0.127]$} & {$[0.125]$} & {$[0.169]$} & {$[0.165]$} & {$[0.152]$} & {$[0.150$} \\
\hline$I F_{s} \times$ Mgmt_Score & 0.038 & 0.028 & $-0.167^{* * *}$ & $-0.166^{* * *}$ & $0.118^{* * *}$ & $0.102^{* * *}$ \\
\hline & $(0.032)$ & $(0.031)$ & $(0.053)$ & $(0.051)$ & $(0.035)$ & $(0.034)$ \\
\hline & {$[0.037]$} & {$[0.036]$} & {$[0.063]$} & {$[0.062]$} & {$[0.040]$} & {$[0.039]$} \\
\hline Mgmt Score & $-0.144^{* * *}$ & $-0.090^{* * *}$ & $0.103^{* * *}$ & $0.135^{* * *}$ & $-0.339^{* * *}$ & $-0.270^{* * *}$ \\
\hline & $(0.029)$ & $(0.029)$ & $(0.034)$ & $(0.034)$ & $(0.036)$ & $(0.036)$ \\
\hline & {$[0.041]$} & {$[0.043]$} & {$[0.044]$} & {$[0.044]$} & {$[0.052]$} & {$[0.054]$} \\
\hline All other (interaction) terms & Yes & Yes & Yes & Yes & Yes & Yes \\
\hline Firm FE & Yes & Yes & Yes & Yes & Yes & Yes \\
\hline Time FE & Yes & No & Yes & No & Yes & $\mathrm{No}$ \\
\hline Ind. $\mathrm{FE} \times$ Time $\mathrm{FE}$ & No & Yes & No & Yes & No & Yes \\
\hline Observations & 638,582 & 638,582 & 317,058 & 317,058 & 321,524 & 321,524 \\
\hline Instruments & & & & & & \\
\hline$\Delta \ln A 1_{s, t}$ & Lag 2 & Lag 2 & Lag 2 & Lag 2 & Lag 2 & Lag 2 \\
\hline$I F_{s} \times \Delta \ln w^{\min } \quad\left(\right.$ and $\times M g m t \_$Score $)$ & Lag 0 & Lag 0 & Lag 0 & Lag 0 & Lag 0 & Lag 0 \\
\hline$\Delta \ln w^{\min } \quad($ and $\times M g m t \quad S c o r \bar{e})$ & Lag 0 & Lag 0 & Lag 0 & Lag 0 & Lag 0 & Lag 0 \\
\hline$I F_{s} \quad\left(\right.$ and $\left.\times M g m t \_S c o r e\right)$ & Lag 0 & Lag 0 & Lag 0 & Lag 0 & Lag 0 & Lag 0 \\
\hline Mgmt_Score & Lag 0 & Lag 0 & Lag 0 & Lag 0 & Lag 0 & Lag 0 \\
\hline Number of instrument & 8 & 8 & 8 & 8 & 8 & 8 \\
\hline$A R(1)$ & -127.18 & -129.85 & -107.55 & -108.36 & -119.77 & -122.39 \\
\hline$A R(2)$ & -6.04 & -4.23 & -8.30 & -6.44 & 4.23 & 5.20 \\
\hline
\end{tabular}




\section{Table 9: Robustness for a Balanced Firm Panel}

We repeat the dynamic panel regression of Table 6 for the total factor productivity (TFP) growth measure $\Delta \ln A 1_{s}$ where we only use firms that report continuously for all sample years to exclude any sample bias due to firm exit or entry. Reported are robust standard errors for the one-step estimator adjusted for clustering at the county/city-year unit in parenthesis and (block) bootstrapped standard errors in brackets which account for the first-stage estimation of the $I F_{s}$.term.

\begin{tabular}{|c|c|c|c|c|c|c|}
\hline & \multicolumn{2}{|c|}{ All firms } & \multicolumn{2}{|c|}{ Low-TFP firms } & \multicolumn{2}{|c|}{ High-TFP firms } \\
\hline & $\begin{array}{l}\text { DGMM } \\
(1)\end{array}$ & $\begin{array}{c}\text { DGMM } \\
(2)\end{array}$ & $\begin{array}{c}\text { DGMM } \\
(3)\end{array}$ & $\begin{array}{c}\text { DGMM } \\
(4)\end{array}$ & $\begin{array}{c}\text { DGMM } \\
(5)\end{array}$ & $\begin{array}{c}\text { DGMM } \\
(6)\end{array}$ \\
\hline$\Delta \ln A 1_{s, t-1}$ & $\begin{array}{r}-0.217^{* * *} \\
(0.004)\end{array}$ & $\begin{array}{r}-0.226^{* * *} \\
(0.004)\end{array}$ & $\begin{array}{r}-0.232^{* * *} \\
(0.006)\end{array}$ & $\begin{array}{r}-0.241^{* * *} \\
(0.005)\end{array}$ & $\begin{array}{r}-0.201^{* * *} \\
(0.005)\end{array}$ & $\begin{array}{r}-0.209^{* * *} \\
(0.005)\end{array}$ \\
\hline$I F_{s} \times \Delta \ln w^{\min }$ & $\begin{array}{c}0.271^{* *} \\
(0.120) \\
{[0.126]}\end{array}$ & $\begin{array}{r}0.311^{* * *} \\
(0.117) \\
{[0.124]}\end{array}$ & $\begin{array}{c}0.484^{* *} \\
(0.225) \\
{[0.227]}\end{array}$ & $\begin{array}{c}0.502^{* *} \\
(0.219) \\
{[0.226]}\end{array}$ & $\begin{array}{r}0.175 \\
(0.133) \\
{[0.139]}\end{array}$ & $\begin{array}{r}0.209 \\
(0.131) \\
{[0.135]}\end{array}$ \\
\hline Level effects $I F_{s}, \Delta \ln w^{\min }$ & Yes & Yes & Yes & Yes & Yes & Yes \\
\hline Firm FE & Yes & Yes & Yes & Yes & Yes & Yes \\
\hline Time FE & Yes & No & Yes & No & Yes & No \\
\hline Ind. $\mathrm{FE} \times$ Time $\mathrm{FE}$ & No & Yes & No & Yes & No & Yes \\
\hline $\begin{array}{l}\text { Observations } \\
\text { Instruments }\end{array}$ & 162,426 & 162,426 & 85,012 & 85,012 & 77,414 & 77,414 \\
\hline$\Delta \ln A 1_{s, t}$ & Lag 2 & Lag 2 & Lag 2 & Lag 2 & Lag 2 & Lag 2 \\
\hline$I F_{s} \times \Delta \ln w^{\min }$ & Lag 0 & Lag 0 & Lag 0 & Lag 0 & Lag 0 & Lag 0 \\
\hline$\Delta \ln w^{\min }$ & Lag 0 & Lag 0 & Lag 0 & Lag 0 & Lag 0 & Lag 0 \\
\hline$I F_{s}$ & Lag 0 & Lag 0 & Lag 0 & Lag 0 & Lag 0 & Lag 0 \\
\hline Number of instruments & 4 & 4 & 4 & 4 & 4 & 4 \\
\hline$A R(1)$ & -79.55 & -80.67 & -64.72 & -64.54 & -67.64 & -68.98 \\
\hline$A R(2)$ & -16.59 & -15.55 & -15.48 & -14.19 & -4.58 & -3.91 \\
\hline
\end{tabular}




\section{Table 10: Exports Effects by Volume and Value}

We use custom trade data to decompose the (log) firm export value into a $(\log )$ value component and a $(\log )$ price component. The log changes in export value, export volume, and export unit price are used as the dependent variables in same panel regression in Columns (1)-(2), (3)-(4), and (5)-(6), respectively. Reported are robust standard errors for the one-step estimator adjusted for clustering at the county/city-year unit in parenthesis and (block) bootstrapped standard errors in brackets which account for the first-stage estimation of the $I F_{s}$ term.

\begin{tabular}{|c|c|c|c|c|c|c|}
\hline & \multicolumn{2}{|c|}{$\begin{array}{c}\text { Export value change } \\
\Delta \ln E x p \_ \text {Value }_{s, t}\end{array}$} & \multicolumn{2}{|c|}{$\begin{array}{l}\text { Export volume change } \\
\Delta \ln \text { Exp_Volume }_{s, t}\end{array}$} & \multicolumn{2}{|c|}{$\begin{array}{l}\text { Unit price change } \\
\Delta \ln E x p \_ \text {Price }_{s, t}\end{array}$} \\
\hline & $\begin{array}{l}\text { DGMM } \\
(1)\end{array}$ & $\begin{array}{c}\text { DGMM } \\
(2)\end{array}$ & $\begin{array}{c}\text { DGMM } \\
(3)\end{array}$ & $\begin{array}{c}\text { DGMM } \\
(4)\end{array}$ & $\begin{array}{c}\text { DGMM } \\
(5)\end{array}$ & $\begin{array}{c}\text { DGMM } \\
(6)\end{array}$ \\
\hline$\Delta \ln E x p \_X_{s, t-1}$ & $\begin{array}{r}-0.096^{* * *} \\
(0.007)\end{array}$ & $\begin{array}{r}-0.096^{* * *} \\
(0.007)\end{array}$ & $\begin{array}{r}-0.055^{* * *} \\
(0.006)\end{array}$ & $\begin{array}{r}-0.058^{* * *} \\
(0.006)\end{array}$ & $\begin{array}{r}-0.047^{* * *} \\
(0.007)\end{array}$ & $\begin{array}{r}-0.049^{* * *} \\
(0.007)\end{array}$ \\
\hline$I F_{s} \times \Delta \ln w^{\min } \times D_{-} S O E$ & $\begin{array}{c}-1.133 \\
(1.159) \\
{[1.258]}\end{array}$ & $\begin{array}{c}-1.151 \\
(1.156) \\
{[1.254]}\end{array}$ & $\begin{array}{c}-0.812 \\
(1.225) \\
{[1.279]}\end{array}$ & $\begin{array}{c}-1.064 \\
(1.220) \\
{[1.283]}\end{array}$ & $\begin{array}{c}-0.171 \\
(0.707) \\
{[0.699]}\end{array}$ & $\begin{array}{r}0.116 \\
(0.701) \\
{[0.6871}\end{array}$ \\
\hline$I F_{s} \times \Delta \ln w^{\min } \times D \_$private & $\begin{array}{c}0.673^{*} \\
(0.387) \\
{[0.435]}\end{array}$ & $\begin{array}{r}0.627 \\
(0.386) \\
{[0.432]}\end{array}$ & $\begin{array}{r}0.439 \\
(0.402) \\
{[0.424]}\end{array}$ & $\begin{array}{r}0.351 \\
(0.398) \\
{[0.419]}\end{array}$ & $\begin{array}{r}0.065 \\
(0.244) \\
{[0.219]}\end{array}$ & $\begin{array}{r}0.121 \\
(0.243) \\
{[0.216]}\end{array}$ \\
\hline$I F_{s} \times \Delta \ln w^{\min } \times D_{\text {_foreign }}$ & $\begin{array}{c}0.428^{* *} \\
(0.203) \\
{[0.188]}\end{array}$ & $\begin{array}{c}0.360^{*} \\
(0.203) \\
{[0.186]}\end{array}$ & $\begin{array}{r}0.639^{* * *} \\
(0.227) \\
{[0.239]}\end{array}$ & $\begin{array}{c}0.485^{* *} \\
(0.225) \\
{[0.235]}\end{array}$ & $\begin{array}{r}-0.282^{*} \\
(0.148) \\
{[0.152]}\end{array}$ & $\begin{array}{c}-0.194 \\
(0.142) \\
{[0.146]}\end{array}$ \\
\hline All other (interaction) terms & Yes & Yes & Yes & Yes & Yes & Yes \\
\hline Firm FE & Yes & Yes & Yes & Yes & Yes & Yes \\
\hline Time FE & Yes & Yes & Yes & Yes & Yes & Yes \\
\hline Ind. $\mathrm{FE} \times$ Time $\mathrm{FE}$ & No & Yes & No & Yes & No & Yes \\
\hline $\begin{array}{l}\text { Observations } \\
\text { Instruments }\end{array}$ & 112,837 & 112,837 & 107,388 & 107,388 & 107,388 & 107,388 \\
\hline$\Delta \ln \operatorname{Exp} \quad X_{s}$ & Lag 2 & Lag 2 & Lag 2 & Lag 2 & Lag 2 & Lag 2 \\
\hline $\bar{I} F_{s} \times \Delta \ln w^{\min } \quad\left(\right.$ and $\left.\times D_{-} x\right)$ & Lag 0 & Lag 0 & Lag 0 & Lag 0 & Lag 0 & Lag 0 \\
\hline$\Delta \ln w^{\min } \quad\left(\right.$ and $\left.\times D \_x\right)$ & Lag 0 & Lag 0 & Lag 0 & Lag 0 & Lag 0 & Lag 0 \\
\hline$I F_{s} \quad\left(\right.$ and $\left.\times D_{-} x\right)$ & Lag 0 & Lag 0 & Lag 0 & Lag 0 & Lag 0 & Lag 0 \\
\hline$D_{-} x$ & Lag 0 & Lag 0 & Lag 0 & Lag 0 & Lag 0 & Lag 0 \\
\hline Number of instruments & 12 & 12 & 12 & 12 & 12 & 12 \\
\hline $\operatorname{AR}(1)$ & -32.86 & -32.86 & -38.87 & -39.10 & -27.12 & -27.51 \\
\hline $\operatorname{AR}(2)$ & -0.11 & -0.17 & 0.54 & 0.54 & -0.23 & -0.20 \\
\hline
\end{tabular}




\section{Appendix A: Firm Effects of Minimum Wage Changes}

The following section derives Propositions 1 and 2 in the paper.

\section{A.1 First-Order Conditions}

The consumer maximization problem for the utility function (5) implies optimal consumption shares

$$
C_{L}=\frac{1}{\left(p_{L}+p_{L}^{\theta}\right)} B, \quad C_{H}=\frac{p_{L}^{\theta}}{\left(p_{L}+p_{L}^{\theta}\right)} B
$$

where $\theta>1$ denotes the elasticity of substitution and we normalize the price of consumption good produced by the high wage firm to $p_{H}=1$. Under market clearing with $Y_{L}=C_{L}$ and $Y_{H}=C_{H}$ we can write the product price $p_{L}$ as a function of product output $Y_{L}$, namely

$$
p_{L}=\left(\frac{Y_{H}}{Y_{L}}\right)^{\frac{1}{\theta}}
$$

and the monopolistic firm value maximization problem implies four first-order conditions

$$
\begin{aligned}
p_{L} \alpha A_{L} K_{L}^{\alpha-1}\left(Q_{L} N_{L}\right)^{1-\alpha} & =\frac{\theta}{\theta-1} r & \alpha A_{H} K_{H}^{\alpha-1}\left(Q_{H} N_{H}\right)^{1-\alpha}=\frac{\theta}{\theta-1} r \\
p_{L}(1-\alpha) A_{L} K_{L}^{\alpha} Q_{L}^{1-\alpha} N_{L}^{-\alpha} & =\frac{\theta}{\theta-1} w_{L} & (1-\alpha) A_{H} K_{H}^{\alpha} Q_{H}^{1-\alpha} N_{H}^{-\alpha}=\frac{\theta}{\theta-1} w_{H}
\end{aligned},
$$

where the average labor quality correspond to the average wage; that is $Q_{L}=w_{L}$ and $Q_{H}=w_{H}$. The equilibrium ratios of profit, output, capital, and labor follow as

$$
\frac{\Pi_{H}}{\Pi_{L}}=\frac{Y_{H} p_{H}-r K_{L}-w_{L} L}{Y_{L} p_{H}-r K_{H}-w_{H} L}=\frac{\frac{1}{\theta} Y_{H} p_{H}}{\frac{1}{\theta} Y_{L} p_{L}}=\frac{Y_{H} p_{H}}{Y_{L} p_{L}}=\frac{K_{H}}{K_{L}}=\frac{L_{H}}{L_{L}}=\left(\frac{A_{H}}{A_{L}}\right)^{\theta-1} .
$$

\section{A.2 Firm Heterogeneity in Average Labor Quality}

The two firms use differ in their average labor quality. If the labor input of each firm $s \in\{H, L\}$ has an average quality $Q_{s}$ measured by the average firm wage $w_{s}$, we can write the quality-adjusted labor input as $L_{s}=w_{s} N_{s}$, where $N_{s}$ denotes the number of employees. Minimum wage changes then have different effects on the average wage of each firm, while the average labor quality cannot adjust in the short run. Let the impact function $I F$ characterize the effect of a minimum wage change $\Delta w^{\min }$ on the average wage of the firm such that

$$
\Delta w_{s}=I F_{s} \Delta w^{\min }
$$

For a minimum wage change $\Delta w^{\text {min }}$, the first-order conditions now imply

$$
\begin{aligned}
p_{L} A_{L}\left(\frac{K_{L}}{L_{L}}\right)^{\alpha-1} & =A_{H}\left(\frac{K_{H}}{L_{H}}\right)^{\alpha-1} \\
p_{L} A_{L}\left(\frac{K_{L}}{L_{L}}\right)^{\alpha} \frac{1}{1+I F_{L} \Delta w^{\min }} & =A_{H}\left(\frac{K_{H}}{L_{H}}\right)^{\alpha} \frac{1}{1+I F_{H} \Delta w^{\min }} .
\end{aligned}
$$


For the equilibrium (value added) output, capital, and labor ratios we obtain

$$
\begin{aligned}
p_{L} & =\frac{A_{H}}{A_{L}}\left(\frac{1+I F_{H} \Delta w^{\mathrm{min}}}{1+I F_{L} \Delta w^{\mathrm{min}}}\right)^{\alpha-1} \\
\frac{Y_{H} p_{H}}{Y_{L} p_{L}} & =\frac{K_{H}}{K_{L}}=\frac{L_{H}}{L_{L}}=\frac{Q_{H} N_{H}}{Q_{L} N_{L}}=\left(\frac{A_{H}}{A_{L}}\left(\frac{1+I F_{H} \Delta w^{\mathrm{min}}}{1+I F_{L} \Delta w^{\mathrm{min}}}\right)^{1-\alpha}\right)^{\theta-1} .
\end{aligned}
$$

Taking logs and using the approximation

$$
\ln \frac{1+I F_{H} \Delta w^{\min }}{1+I F_{L} \Delta w^{\min }} \approx\left(I F_{H}-I F_{L}\right) \Delta w^{\min }
$$

implies the relationships stated in Propositions 1 and 2.

\section{Appendix B: Sample Construction}

Our data source is the Annual Survey of Industrial Firms during the period 1998-2008. The survey reports on industrial firms from the mining, manufacturing, and public utility sectors. This section describes the data-cleaning and filtering procedure used for obtaining the sample used in the analysis.

\section{B.1 Data Cleaning}

The raw data comprise 2,615, 016 firm-year observations, corresponding to 666, 554 distinct firms. We apply consecutively the following data-cleaning operations:

1. We drop firm-year observations with missing, zero, or negative values for total assets, output, book value of fixed assets, operating revenues, and employment. In addition, we drop firm-year observations for which operating status are not reported as "normal". This implies dropping 105, 476 firm-year observations (or 4\%).

2. We drop firm-year observations with fewer than eight employees.

3. We drop firm-year observations with revenue (sales) or output lower than 10,000 Yuan or revenues per employee or output per employee lower than 1,000 Yuan.

4. We drop firms that do not report a correct location code for every firm-year.

The gross sample has 2,442, 439 firm-year observations, corresponding to 619,877 distinct firms.

\section{B.2 Data Filtering}

Next, we apply a series of data filters that exclude firm-year observations outside a reasonable range of variable variation. Such observations are likely to represent reporting errors or just extreme firm events discarded from the sample. The following filters are applied sequentially: 
1. For every observation in our regressions, we require that the corresponding (one-year) lagged observation exists. A missing lagged observation implies that the contemporaneous observation is not used in the analysis. 668,147 firm-year observations are thus excluded.

2. We exclude firm-year observations for which the real minimum wage changes feature extreme negative correlation for two consecutive years, namely if $\Delta w_{t}^{\min } \times \Delta w_{t-1}^{\min }<-0.04$. This accounts for 3,540 discarded firm-year observations.

3. We exclude 486, 403 firm-year observations if certain critical variables are below the $1 \%$ quantile or above the $99 \%$ quantile of its annual distribution. These critical variable are the following:

(a) The ratio of the local minimum wage to the firm wage, where firm wage is defined as the average employee wage.

(b) Firm wage growth demeaned by firm wage growth at the city level.

(c) The growth rate of output per employee, capital stock per employee, and intermediate input per employee, all demeaned at the city level.

(d) The growth rate of firm value-added, firm capital, firm employment, and firm TFP $A 1$, all demeaned at the city level.

4. As minimum wage legislation became more stringently enforced in the later years of the sample, we focus most of our analysis on the period 2002-08. Data for the years 2000-01 only enters as lagged dependent and instrumental variable data.

The final sample for our regressions has 1,190, 070 firm-year observations for the period 2002-08, corresponding to 365,813 different firms.

\section{B.3 Summary Statistics}

We divide firms into three size groups according to the number of employees. Small firms have 8-200 employees, medium-size firms 201-1,000 employees and large firms more than 1,000 employees. The number of firms covered increases over time. The exception here is the year 2008, for which value added is not directly reported. Instead we have to infer value added in 2008 using the reported operating costs, which results more frequently in missing values.

Table A1 reports summary statistics on the number of firms by size, aggregate employment and output. Additional summary statistics on each variable are reported in Table 1 of the paper. The sample coverage of small firms is particularly incomplete in the early period 2002-04. 
Table A1: Sample Observations and Coverage of the Industrial Sector

\begin{tabular}{|c|c|c|c|c|c|c|}
\hline \multirow[t]{3}{*}{ Year } & \multicolumn{4}{|c|}{ Firm Observations } & \multicolumn{2}{|c|}{ Sample Aggregates } \\
\hline & Small & Medium & Large & All & Employment & $\begin{array}{c}\text { Output } \\
\text { (Million Yuan) }\end{array}$ \\
\hline & $(1)$ & $(2)$ & $(3)$ & $(4)$ & $(5)$ & $(6)$ \\
\hline 2002 & 68,137 & 34,118 & 6,475 & 108,730 & $39,816,386$ & $8,070,262,467$ \\
\hline 2003 & 75,853 & 36,305 & 6,632 & 118,790 & $41,597,119$ & $9,997,379,425$ \\
\hline 2004 & 80,085 & 36,489 & 6,390 & 122,964 & $40,905,196$ & $12,209,453,344$ \\
\hline 2005 & 133,025 & 47,612 & 7,448 & 188,085 & $51,961,894$ & $17,626,426,925$ \\
\hline 2006 & 141,613 & 50,751 & 8,122 & 200,486 & $56,711,052$ & $22,977,664,979$ \\
\hline 2007 & 160,643 & 54,713 & 8,545 & 223,901 & $60,796,602$ & $30,150,039,329$ \\
\hline 2008 & 166,598 & 52,600 & 7,916 & 227,114 & $57,368,513$ & $32,810,179,824$ \\
\hline
\end{tabular}

\section{B.4 Factor Productivity Measurement}

Here we describe the construction of the four different measures of total factor productivity (TFP). The firm (net) output measure used in the analysis is value added defined as the difference between (deflated) gross revenue and the (deflated) value of the intermediary good inputs; formally

$$
Y=\text { Gross Revenue } / p_{Y}-\text { Cost Intermediary Goods } / p_{X},
$$

where $p_{Y}$ and $p_{X}$ denote the industry output price index and the intermediary good price index, respectively. Total $(\log )$ total factor productivity (TFP) growth is defined as the change in the difference between log net output value and the value of labor input and capital costs at constant lagged firm wages $w_{t-1}$ and constant lagged factor shares $\alpha_{L}$ and $\alpha_{K}$,

$$
\Delta \ln A_{t}=\ln A_{t}-\ln A_{t-1}=\ln Y_{t}-\ln Y_{t-1}-\alpha_{L}\left(\ln w_{t-1} N_{t}-\ln w_{t-1} N_{t-1}\right)-\alpha_{K}\left(\ln K_{t}-\ln K_{t-1}\right) .
$$

This implies that TFP growth is measured in terms of labor and capital input and not affected by contemporaneous changes in firm wages. We assume that the labor and capital share of production, $\alpha_{L}$ and $\alpha_{K}$, respectively, add up to 1 . Cost minimization implies that the optimal factor inputs correspond to the labor and capital share of production. We use a wage-based labor input measure, but apply lagged firm wages $w_{t-1}$ to exclude any effect of contemporaneous wages on the calculation of the labor share

$$
\alpha_{L}=\alpha_{L}(i, t)=\frac{w_{t-1} N_{t}}{w_{t-1} N_{t}+r K_{t}} .
$$

For the cost of capital we assume a constant rate $r=7 \%$ for all firms. 
Next we define the four different TFP growth measures $(n=0,1,2,3)$

$$
\Delta \ln A n_{t}=\ln Y_{t}-\ln Y_{t-1}-\widehat{\alpha}_{L}^{n}\left(\ln w_{t-1} N_{t}-\ln w_{t-1} N_{t-1}\right)-\left(1-\widehat{\alpha}_{L}^{n}\right)\left(\ln K_{t}-\ln K_{t-1}\right)
$$

These differ in their use of the particular labor shared used. The first total productivity measure $\ln A 0$ is based on productivity parameter $\widehat{\alpha}_{L}^{0}$ equal to the firm- and year-specific labor share $\alpha_{L}(i, t)$; therefore

$$
\widehat{\alpha}_{L}^{0}=\alpha_{L}(i, t)
$$

This measure allows for firm- and time-specific variation of the labor share. The second total total factor productivity measure $\ln A 1$ is based on a productivity parameter $\widehat{\alpha}_{L}^{0}$ averaging all time observations $T(i)$ available for a firm; that is

$$
\widehat{\alpha}_{L}^{1}=\frac{1}{\sharp T(i)} \sum_{t \in T(i)} \alpha_{L}(i, t) .
$$

This measure of total factor productivity should give good results if the optimal labor share of a firm is reasonably constant over time. The third total productivity measure $\ln A 2$ does not assume such time invariance, but instead averages the labor share of production of all firms $I(i)$ in the same industry as firm $i$; therefore

$$
\widehat{\alpha}_{L}^{2}=\frac{1}{\sharp I(i)} \sum_{i \in I(i)} \alpha_{L}(i, t) .
$$

The quality of this measure depends on the industry homogeneity with respect to the labor share. The fourth total productivity measure $\ln A 3$ is based on a labor share estimate that minimizes the time and cross-sectional variation of $\alpha_{L}(i, t)$. We undertake a panel regression

$$
\alpha_{L}(i, t)=\gamma_{0}+\gamma_{T} D_{T}+\gamma_{I} D_{I}+\epsilon
$$

using matrices of firm dummies $D_{\text {Firm }}$ and interacted industry and year dummies $D_{\text {Ind } \times \text { Year }}$ as regressors and define

$$
\widehat{\alpha}_{L}^{3}=\widehat{\gamma}_{0}+\widehat{\gamma}_{1} D_{\text {Firm }}+\widehat{\gamma}_{2} D_{\text {Ind } \times Y e a r} .
$$

The last measure generalizes the previous two in the sense that $\widehat{\alpha}_{L}^{3}=\widehat{\alpha}_{L}^{1}$ if we impose the restriction $\gamma_{2}=0$ and $\widehat{\alpha}_{L}^{3}=\widehat{\alpha}_{L}^{2}$ if we impose the restriction $\gamma_{1}=0$.

\section{Appendix C: Minimum Wage Determination}

We explores which local variables influence the minimum wage changes $\Delta \ln w^{\min }$ in China at the country/city level and measure wage growth, changes in the unemployment rate, output growth, and TFP growth at the county/city level. We also break down firm performance in year $t-1$ by firm ownership type (SOEs, private-owned firms, and foreign-owned firms located in the country/city), where the performance measures are (firm size weighted) output growth in Column (2), TFP growth in Column (3), and stocks returns in Columns (4). 
Table A2: Determinants of Minimum Wage Changes $\Delta \ln w^{\min }$

(1)

$(2)$

(3)

(4)

(Log of) county/city minimum wage to

average province minimum wage in $t-1$

$$
\begin{array}{rrrr}
0.464^{* * *} & 0.464^{* * *} & 0.460^{* * *} & 0.464^{* * *} \\
(0.065) & (0.073) & (0.074) & (0.065) \\
-0.016 & -0.063 & -0.058 & -0.016 \\
(0.053) & (0.055) & (0.053) & (0.053) \\
0.085 & 0.006 & 0.024 & 0.085 \\
(0.126) & (0.142) & (0.139) & (0.126) \\
-0.000 & & & \\
(0.007) & & & \\
0.001 & & & \\
(0.009) & & &
\end{array}
$$$$
\begin{array}{llll}
(0.065) & (0.073) & (0.074) & (0.065)
\end{array}
$$

County/city wage growth in $t-1$

$\begin{array}{llll}-0.016 & -0.063 & -0.058 & -0.016\end{array}$

$\begin{array}{llll}(0.053) & (0.055) & (0.053) & (0.053)\end{array}$

County/city unemployment change in $t-1$

0.006

0.024

0.085

County/city output growth in $t-1$

$(0.142)$

$(0.139)$

$(0.126)$

County/city TFP growth in $t-1$

Output growth of SOEs in $t-1$

$-0.002$

$(0.002)$

Output growth of private firms in $t-1$

$-0.000$

$(0.003)$

0.003

Output growth of foreign firms in $t-1$

TFP growth of SOEs in $t-1$

$$
-0.004
$$

0.007

TFP growth of private firms in $t-1$

TFP growth of foreign firms in $t-1$

$0.006^{*}$

$(0.003)$

Stock returns of SOEs in $t-1$

$-0.000$

Stock returns of private firms in $t-1$

$-0.003$

(0.004)

Stock returns of foreign firms in $t-1$

0.007

$(0.005)$

Observations

15,583
0.058
Yes
Yes
No

10,622

11,399

15,609

Adjusted $R^{2}$

0.081

0.080

0.058

Year FE

Province FE

$\mathrm{FE}$ for missing values in stock return

Yes Yes

Yes

Yes

No

Yes

Yes

No Yes 